ROSANGELA SAYURI SAGA KAMIKAWA

\title{
PESQUISA DE CALCIFICAÇÕES EM TECIDOS MOLES NA REGIÃO CERVICAL POR MEIO DAS TÉCNICAS RADIOGRÁFICAS \\ PANORÂMICA E TELERRADIOGRAFIA
}

São Paulo

2009 
Rosangela Sayuri Saga Kamikawa

Pesquisa de calcificações em tecidos moles na região cervical por meio das técnicas radiográficas panorâmica e telerradiografia

Tese apresentada à Faculdade de Odontologia da Universidade de São Paulo, para obter o título de Doutor, pelo programa de Pós-Graduação em Odontologia.

Área de Concentração: Diagnóstico Bucal

Orientadora: Prof $^{\mathrm{a}}$. Dr ${ }^{\mathrm{a}}$. Marlene Fenyo-Pereira

São Paulo

2009 
Kamikawa, Rosangela Sayuri Saga

Pesquisa de calcificações em tecidos moles na região cervical por meio das técnicas radiográficas panorâmica e telerradiografia / Rosangela Sayuri Saga Kamikawa; orientador Marlene Fenyo-Pereira.

-- São Paulo, 2009.

76p. : fig., tab., graf.; $30 \mathrm{~cm}$.

Tese (Doutorado - Programa de Pós-Graduação em

Odontologia. Área de Concentração: Diagnóstico Bucal) -- Faculdade de Odontologia da Universidade de São Paulo.

1. Telerradiografia - Norma lateral e frontal - Radiopacidade Região cervical $\quad$ 2. Telerradiografia - Radiografia panorâmica Comparação 3. Diagnóstico bucal 4. Arteriosclerose 
AUTORIZO A REPRODUÇÃO E DIVULGAÇÃO TOTAL OU PARCIAL DESTE TRABALHO, POR QUALQUER MEIO CONVENCIONAL OU ELETRÔNICO, PARA FINS DE ESTUDO E PESQUISA, DESDE QUE CITADA A FONTE E COMUNICADA AO AUTOR A REFERÊNCIA DA CITAÇÃO.

São Paulo,

Assinatura:

E-mail:

\section{FOLHA DE APROVAÇÃO}

Kamikawa RSS. Pesquisa de calcificações em tecidos moles na região cervical por meio das técnicas radiográficas panorâmica e telerradiografia [Tese de Doutorado]. São Paulo: Faculdade de Odontologia da USP; 2009.

São Paulo $/ 2009$

\section{Banca Examinadora}

1) $\operatorname{Prof}(a) \cdot \operatorname{Dr}(a)$.

Titulação:

Julgamento: Assinatura:

2) $\operatorname{Prof}(a) \cdot \operatorname{Dr}(a)$.

Titulação:

Julgamento: Assinatura:

3) $\operatorname{Prof}(\mathrm{a}) . \operatorname{Dr}(\mathrm{a})$.

Titulação: 
Julgamento:

Assinatura:

4) $\operatorname{Prof}(a) . \operatorname{Dr}(a)$.

Titulação:

Julgamento: Assinatura:

5) $\operatorname{Prof}(a) . \operatorname{Dr}(a)$.

Titulação:

Julgamento: Assinatura:

DEDICATÓRIA

Ao meu marido Wagner Kamikawa

"Compartilha minhas alegrias nos bons momentos e ajuda a recuperar-me durante os maus. Ouve com sensibilidade necessária para escutar-me de verdade, olha com a profundidade necessária para me ver de verdade, e sempre encontra uma forma de fazer-me que sou importante para você."

À minha filha Rafaela Saga Kamikawa

“...Nunca se esqueça nem um segundo que eu tenho o amor maior do mundo. Como é grande o meu amor por você..."

Aos meus pais Tsutomo e Yoshiko Saga

"Queria retribuir, de alguma forma, tudo o que me deram tornando minha vida tão plena: o calor de suas companhias, a profundidade de suas compreensões, a constância dos 
teus apoios. Não me pedem nada, apesar de que tudo que eu pudesse dar algum dia, nunca seria demasiado". Dedico à vocês esta conquista.

Aos meus irmãos Clécia, Noemi e Armando

"À medida que avançamos e recordamos todos os momentos compartilhados compreendemos que, apesar das mudanças, das circunstâncias, das novas famílias que formamos,

o laço que nos une desde a infância se mantém e é um sentimento incomparável"

\section{AGRADECIMENTO ESPECIAL}

À minha Orientadora e amiga Profa. Dra. Marlene Fenyo-Pereira, sua generosidade jamais espera que o agradecimento seja a retribuição ao que você faz por mim ou pelos outros.

Contar com sua amizade, poder confiar em você, receber seu apoio é muito valioso para minha vida.

À minha mãe,

Que sempre está ao meu lado me apoiando e me incentivando para tornar-me uma pessoa capaz de enfrentar com dignidade as adversidades da vida. 



\section{AGRADECIMENTOS}

Ao Prof. Monir Tacla, Diretor do Curso de Odontologia da Pontifícia Universidade Católica do Paraná. Minha gratidão pelo acolhimento para a realização desta pesquisa, pelo apoio e pela confiança depositada em mim.

Ao Prof. Dr. Cláudio Froes de Freitas, pela amizade, dedicação prestada a minha formação acadêmica, profissional, pessoal e oportunidade de convivência proporcionada durante os últimos anos.

Aos professores da disciplina de Radiologia pelo convívio e ensinamentos transmitidos.

Aos alunos da pós-graduação pelo agradável convívio nesses anos.

Às minhas amigas Alessandra Coutinho, Ana Lúcia Tolazzi, Fábia Hayama, Luciana Reis Azevedo, Mariza Chonan Shibue, Sibele Pereira de Oliveira, Sandra Cardoso, Silvia D’Pólito, Vânia Dacheux, agradeço pela amizade, pelo amparo, pelas horas incertas, pelo respeito, pelo carinho. Meu sincero obrigado por estarem sempre presentes, não só nos momentos de alegria, mas principalmente nos momentos mais difíceis...

Aos Professores Dra. Ângela Fernandes e Dr. Fernando Henrique Westphalen, pelo apoio à vida acadêmica, pelo incentivo que sempre recebi na Universidade Federal do Paraná.

Ao Dr. Henrique Taglianetti e sua família, pela amizade compartilhada ao longo desses anos.

Ao Prof. Dr. Aguinaldo Nascimento, pela paciência e inestimável orientação na análise estatística. 


\section{AGRADECIMENTOS}

À Kassandra Assolari Costa, radiologista e técnica do serviço de radiologia da Pontifícia Universidade Católica do Paraná, pelo auxílio nas realizações das radiografias e pela sua generosidade. Um singelo muito obrigado talvez não alcance em comparação com a ajuda que recebi.

À Acir José da Silva Franco, responsável pelo Laboratório de Anatomia da Pontifica Universidade Católica do Paraná, pela dedicação, pelo auxílio e participação das dissecações das cabeças de cadáveres.

À Maria Cecília Forte Muniz pela presteza dos seus serviços, e pela sua dedicação aos alunos e professores da Radiologia.

A todos os Radiologistas que participaram e colaboraram com a pesquisa.

Às bibliotecárias Vânia Martins Bueno de O. Funaro, Luzia M. Zoppei Murgia e Moraes, Glauci E.D. Fidelis e Maria Aparecida Pinto pela relevante colaboração na efetivação e conclusão deste trabalho.

Á Alessandra Moreira de Lima, Kátia Tiezzi dos Santos e Nair Hatsuko Tanaka Costa pelos serviços prestados à pós-graduação. 
Kamikawa RSS. Pesquisa de calcificações em tecidos moles na região cervical por meio das técnicas radiográficas panorâmica e telerradiografia [Tese de Doutorado]. São Paulo: Faculdade de Odontologia da USP; 2009.

\section{RESUMO}

A literatura tem alertado para a presença de imagens radiopacas em radiografias panorâmicas, adjacentes à coluna cervical, indicativas de calcificações na bifurcação da artéria carótida, representando indícios da presença de ateromas. Diferentes imagens radiopacas podem ser observadas na região cervical (anatômicas e patológicas), cujas características devem ser conhecidas. Existem, no entanto, considerações a serem feitas em relação a diferentes constituições físicas entre sexos, raças, e mesmo relacionadas ao tipo físico do indivíduo, que podem produzir projeções diferenciadas nas radiografias panorâmicas. A interpretação dessas radiografias requer uma compreensão da formação das imagens, já que a radiografia panorâmica é um sistema rotacional que resulta na formação de uma zona de nitidez dentro da qual as estruturas aparecem em foco e as que estivem para fora aparecerão borradas. O objetivo do trabalho foi avaliar a contribuição das telerradiografias, nas normas lateral e frontal, na identificação e localização de calcificações em tecidos moles, quando comparado com as observadas em radiografia panorâmica. Referências radiopacas em guta percha foram posicionadas unilateralmente, em três cabeças de cadáveres, procurando manter sempre no mesmo nível da bifurcação da artéria carótida comum, em diferentes 
estruturas, sítios de possíveis calcificações e foram obtidas três incidências radiográficas para cada peça anatômica. Assim, a amostra deste estudo foi composta por 27 radiografias panorâmicas, 27 telerradiografias em norma lateral e 27 telerradiografias em norma frontal, totalizando 81 radiografias. Estas imagens foram avaliadas por 05 examinadores para que identificassem qual a localização mais provável da referência radiopaca e se as telerradiografias em norma lateral e frontal auxiliaram no diagnóstico diferencial das calcificações, quando observadas na radiografia panorâmica. Os resultados obtidos apontaram que as telerradiografias em norma lateral e frontal não contribuem eficazmente na identificação e localização de radiopacidades na região cervical, e que a conformação anatômica interfere na observação da presença de radiopacidade na região cervical.

Palavras-Chave: Acidente vascular cerebral; Arteriosclerose; Radiografia panorâmica 
Kamikawa RSS. Research on calcifications in soft tissues in the cervical region by means of panoramic radiographic and teleradiographic techniques [Tese de Doutorado]. São Paulo: Faculdade de Odontologia da USP; 2009.

\begin{abstract}
The literature has warned about the presence of radiopaque images in panoramic radiographs, adjacent to the spine, indicative of calcifications in the bifurcation of the carotid artery, representing signs of the presence of atheromas. Different radiopaque images can be observed in the cervical region (anatomic and pathologic), whose characteristics should be known. There are, however, considerations to be made with regard to the different physical constitutions between sexes, races, and even related to the physical type of the individual, which may produce differentiated projections in panoramic radiographs. Interpretation of these radiographs requires an understanding of the formation of the images, since the panoramic radiograph is a rotational system that results in the formation of a zone of nitidity within which the structures appear in focus and those that are outside of it appear blurred. The aim of the study was to evaluate the contribution of lateral and frontal teleradiographs to the identification and location of calcifications in soft tissues, when compared with those observed in panoramic radiographs. Radiopaque references in gutta percha were placed unilaterally on the heads of three cadavers, endeavoring at all times to keep to the same level as the bifurcation of the common carotid artery in different structures, sites of possible calcifications, and three radiographic incidences were obtained for each anatomic part.
\end{abstract}


Thus, the sample of this study was composed of 27 panoramic radiographs, 27 lateral teleradiographs and 27 frontal teleradiographs, totaling 81 radiographs. These images were evaluated by 05 examiners so that they could identify which the most probable location of the radiopaque reference would be, and whether the lateral and frontal teleradiographs were a help in the differential diagnosis of the calcifications, when observed in the panoramic radiograph. The results obtained showed that the lateral and frontal teleradiographs did not contribute efficiently to the identification and location of radiopacities in the cervical region, and that the anatomic conformation interferes in the observation of the presence of radiopacity in the cervical region.

Keywords: Cerebral vascular accident; Arteriosclerosis; Panoramic radiography 


\section{SUMÁRIO}

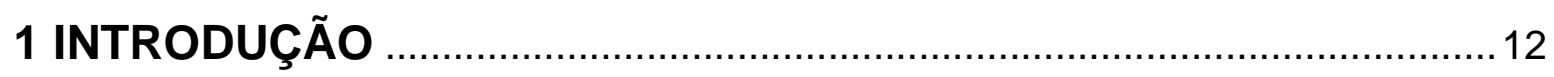

2 REVISÃO DA LITERATURA …........................................................... 15

2.1 Calcificações na região da artéria carótida .............................................. 15

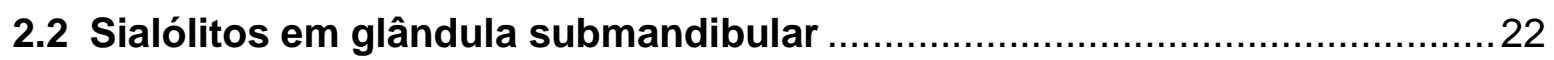

2.3 Calcificações das cartilagens tireóidea, tritícea e a

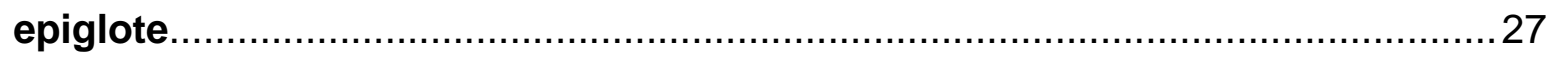

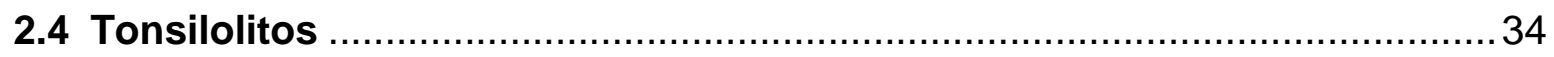

2.5 Mineralizações/Calcificações dos ligamentos

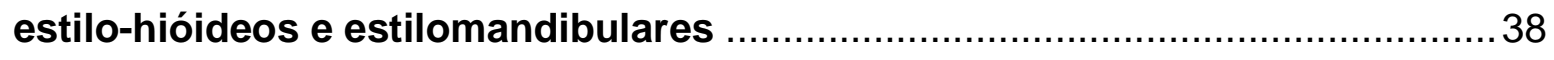

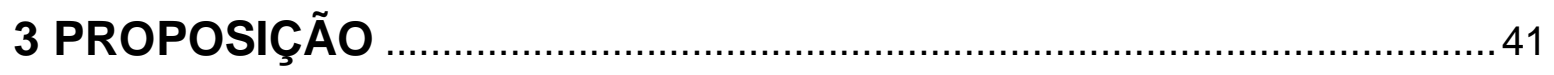

4 MATERIAL E MÉTODOS ................................................................ 42

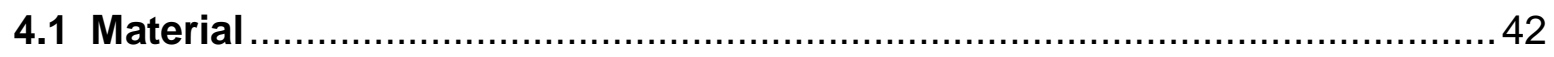

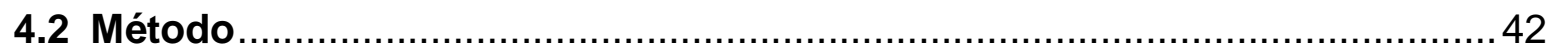

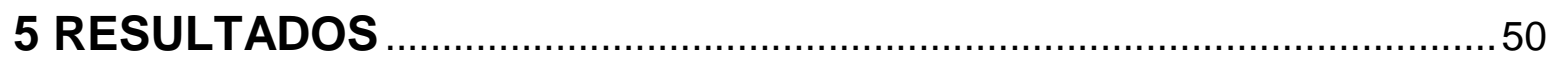

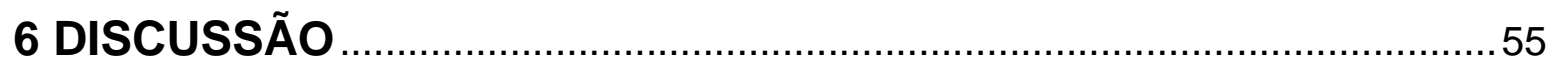

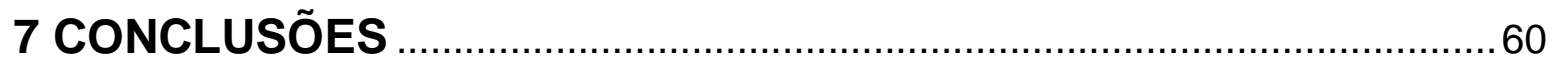

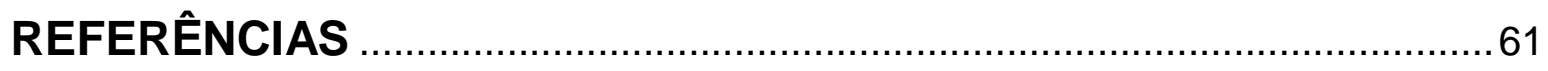

ANEXOS

APÊNDICES 


\section{INTRODUÇÃO}

A arteriosclerose é o termo médico utilizado para um grupo de doenças nas quais as paredes arteriais sofrem espessamento e perdem a elasticidade. A aterosclerose é uma forma distinta de arteriosclerose em que placas amareladas se formam dentro de artérias de grande e médio calibre. As doenças ateroscleróticas relacionadas com a formação de trombos e êmbolos na bifurcação da artéria carótida comum e/ou artéria carótida interna é a causa mais comum de acidente vascular cerebral (envolvido em 60 por cento dos casos), segundo Gelabert e Moore (1991). Tais lesões muitas vezes são parcialmente calcificadas e podem ser observadas em radiografias panorâmicas e em radiografias planas de crânio, ossos faciais e coluna cervical (FRIEDLANDER; GRATT, 1994).

A radiografia panorâmica é o exame radiográfico extra-oral mais utilizado na Odontologia, fornecendo uma visão ampla do complexo dento-bucomaxilofacial. As calcificações em tecidos moles, quando presentes, podem ser observadas por meio desse exame, mas faz-se necessário conhecer os princípios de interpretação neste tipo de exame para identificar estas calcificações nas regiões de cabeça e pescoço. A literatura tem alertado para a presença de imagens radiopacas em radiografias panorâmicas, adjacentes à coluna cervical, indicativas de calcificações na bifurcação da artéria carótida, representando indícios da presença de ateromas (CARTER, 2000; FRIEDLANDER, 1995). 
Friedlander e Lande (1981) foram os primeiros a relatar a respeito da freqüência da ocorrência de placas ateroscleróticas nas radiografias panorâmicas. Nos seus estudos sugeriram que radiografias panorâmicas eram capazes de desempenhar um papel significativo no diagnóstico de ateromas calcificados de artéria carótida, os quais poderiam degenerar em doenças mais graves cerebrovasculares e doenças cardíacas. Diferentes imagens radiopacas podem ser observadas na região cervical (anatômicas e patológicas), cujas características devem ser conhecidas. Kamikawa et al. (2006) afirmaram que calcificação da cartilagem tritícea deve ser considerada como estrutura que pode ser confundida com ateroma calcificado em artéria carótida, devido a localização de sua imagem na panorâmica.

Existem, no entanto, considerações a serem feitas em relação a diferentes constituições físicas entre sexos, raças, e mesmo relacionadas ao tipo físico do indivíduo, que podem produzir projeções diferenciadas nos exames radiográficos.

Historicamente, os cirurgiões-dentistas utilizavam radiografias cefalométricas laterais para avaliar características morfológicas faciais de crianças e adolescentes em crescimento, isto é, pessoas de baixo risco de desenvolver aterosclerose. Recentemente, no entanto, os cirurgiões-dentistas utilizam esta modalidade de imagem para avaliação de pacientes adultos que procuram tratamento ortodôntico, implantes e terapia de apnéa do sono. A prevalência de aterosclerose em artéria carótida entre estes pacientes é, sem dúvida, maior, tornando assim, benéfica a atenção dos cirurgiões-dentistas para a observação de ateromas calcificados nas radiografias cefalométricas. Muitos cirurgiões-dentistas poderiam auxiliar da prevenção de determinadas doenças, especialmente aqueles que tratam um grande número de 
pacientes acima de 40 anos e para aqueles que utilizam esse exame para algum tipo de avaliação odontológica (FRIEDLANDER; DOUNIS; GRATT, 1996).

Nas radiografias panorâmicas, ainda existem dúvidas quanto à localização exata dessas calcificações em tecidos moles, o que pode levar a erros de interpretação justificando assim, a realização deste estudo utilizando as telerradiografias laterais e frontais como incidências radiográficas complementares no diagnóstico. 


\section{REVISÃO DA LITERATURA}

\subsection{Calcificações na região da artéria carótida}

O difundido reconhecimento de que as calcificações observadas na região da bifurcação carotídea podem identificar uma população em maior risco de acidente vascular cerebral, apóia a prática de um exame de rotina nesta área durante análise das radiografias panorâmicas. Uma vez que uma radiografia panorâmica é frequentemente obtida por motivos odontológicos, em muitos casos, um exame mais aprofundado da área da bifurcação carotídea pode servir para prolongar a vida e trazer economias significativas aos custos dos cuidados de saúde global, auxiliando na prevenção de eventos críticos, tais como acidentes vasculares cerebrais (ALMOG et al., 2004).

Romano-Sousa et al. (2009) realizaram um estudo para investigar a concordância entre os diagnósticos de ateromas calcificados observados em radiografias panorâmicas e imagens em Doppler colorido. As imagens panorâmicas podem mostrar a presença de ateroma, independentemente do nível de obstrução detectada pelas imagens em Doppler colorido. Os autores concluíram que as radiografias panorâmicas podem ajudar a detectar calcificações na região cervical de pacientes suscetíveis a doenças vasculares predisponentes ao infarto do miocárdio e acidentes vasculares cerebrais.

Tamura et al. (2005) analisaram 2568 radiografias de pacientes cujas dades variavam de 50 a 70 anos. A média de idade dos indivíduos foi de 62,2 anos (homens 
61,9 anos; mulheres 62,3 anos). Foram coletados dados médicos e sociais, peso corporal, altura e idade da menopausa. Cerca de 106 calcificações em artérias carótidas foram encontradas em radiografias panorâmicas de 26 homens e 80 mulheres. Os indivíduos com calcificações em carótida tinham históricos médicos que incluíram hipertensão (27,6\%), obesidade (21,1\%), hiperlipidemia (14,5\%), e as doenças cardiovasculares $(13,2 \%)$, todos reconhecidos como fatores de risco para ateromas. Dos 76 pacientes que estavam em acompanhamento por meio de entrevistas, dois $(2,63 \%)$ morreram de acidente cardiovascular cerebral durante uma média de acompanhamento de 2,4 anos. A taxa de incidência de ateromas calcificados de artéria carótida no gênero feminino $(5,94 \%)$ foi aproximadamente três vezes maior do que a taxa entre os do gênero masculino $(2,13 \%)$. O resultado das mulheres terem uma maior incidência significativa de ateromas calcificados de artéria carótida sugere uma relação entre o declínio nos níveis de estrogênio e o ateroma carotídeo calcificado. O declínio nos níveis de estrogênio no sangue de mulheres pós-menopausa é considerado ser um fator que contribui para ateromas calcificados de artéria carótida.

Friedlander e Altoman (2001) relataram que o estrogênio diminui o catabolismo da lipoproteína de baixa densidade (LDL) no sangue e que os níveis aumentados de LDL no sangue foram associados com atividade da lipase hepática, levando as paredes dos vasos a endurecer e engrossar. Os indivíduos neste estudo tinham entre 50 e 70 anos, e de todos os pacientes do gênero feminino, que responderam ao exame de acompanhamento eram mulheres pós-menopáusicas.

A bifurcação carotídea cervical é um dos locais mais comuns da placa ateromatosa. Em grandes estudos clínicos, endarterectomia carotídea profilática para pacientes com alto grau estenose foi provado ser mais benéfico do que a terapia 
medicamentosa (EUROPEAN CAROTID SURGERY TRIALISTS' COLLABORATIVE GROUP, 1998; NORTH AMERICAN SYMPTOMATIC CAROTID ENDARTERECTOMY TRIAL COLLABORATORS, 1991) e a colocação de stent de artéria carótida também tem sido considerado uma alternativa para a endarterectomia carotídea profilática em pacientes de alto risco, segundo Yadav et al. (2004).

É bem sabido que a distribuição da placa ateromatosa é limitada, razão pela qual endarterectomia carotídea e colocação de stent de artéria carótida são mais benéficos do que a terapia medicamentosa. Vários estudos têm descrito a localização da placa ateromatosa, embora existam poucos relatos detalhados. Sabe-se também que a artéria carótida comum é uma artéria elástica, considerando que a artéria carótida interna é uma artéria muscular e a artéria elástica muda para artéria muscular na bifurcação da carótida.

No estudo realizado por Hori et al., 2008 a placa ateromatosa na bifurcação carotídea foi encontrada na zona de transição entre a artéria elástica para artéria muscular, uma mudança que surgiu para influenciar na formação da placa ateromatosa. Há muitos relatos sobre as causas do desenvolvimento da placa ateromatosa em torno da bifurcação da carótida (AFFELD et al., 1998; SCHULZ; ROTHWELL, 2001; ZARINS et al., 1983)

Klosek e Rungruang (2008) realizaram um estudo cujo objetivo foi descrever a bifurcação da artéria carótida comum em relação às estruturas adjacentes para localizála corretamente, usando marcos externo e interno. As medições foram realizadas em 43 cadáveres tailandeses pelo método de inspeção direta. O sítio da bifurcação carotídea foi comparado com o nível da vértebra cervical, istmo da cartilagem tireóidea, ângulo da mandíbula e as origens da artéria tireoidiana superior e artéria lingual. A maioria das 
bifurcações carotídeas foi encontrada na altura de C3, entre C3 e C4, e vértebra C4, bem como foi notada a tendência para uma posição mais inferior em homens. Neste estudo, a maior parte das bifurcações carotídeas foi encontrada na altura das vértebras C3 e C4, porém dois casos de alta bifurcações carotídeas, à nível das vértebras C2 e C3 foram notadas unilateralmente, que foi de $2,7 \%$ de todas as bifurcações carotídeas. Segundo a literatura, a incidência desta variação é rara, cerca de 1\% (GLUNCIC et al., 2001). A presença de bifurcação alta requer cautela dos cirurgiões para não lesionar o nervo hipoglosso, o qual passa entre a artéria carótida interna e a veia jugular interna (ASSADIAN et al., 2004). Além disso, foi encontrada alta incidência de bifurcações em níveis mais baixos, abaixo da vértebra C4. No grupo dos homens, foi observada em $30,7 \%$ e no grupo das mulheres, foi encontrado em $17,9 \%$ de todas as bifurcações carotídeas. Em outros estudos, as artérias carótidas comuns bifurcaram normalmente, no nível de C3 e C4, porém em 10\% dos casos, a bifurcação carotídea foi encontrada no nível de C2, e apenas em 1\% estava ao nível de C5 (ANU et al., 2007). A ausência unilateral ou bilateral de artéria carótida externa foi relatada por Bergman et al. (1998).

Nos estudos de Klosek e Rungruang (2008) foram notados quatro casos de ausências bilaterais de bifurcações carotídeas, isto é, ausências de 8 (oito) bifurcações e de outros quatro casos, de ausências unilaterais, totalizando assim, 12 (doze) bifurcações carotídeas que não estavam presentes no pescoço em 86 locais considerados (13,9\%). A ausência completa de ambas as artérias carótidas comuns foi relatado por Roberts e Gerald (1978).

A embriologia de artérias carótidas pode explicar as variações da localização da bifurcação carotídea, bem como, a existência de apenas um tronco arterial. A artéria carótida comum e a parte proximal da artéria carótida interna se desenvolvem no nível 
do terceiro arco aórtico, e o resto da artéria carótida interna se desenvolve a partir da porção cranial da aorta dorsal; porém ramos da artéria carótida externa, a partir do terceiro arco aórtico. Assim, a posição da bifurcação carotídea depende de quão alta ou baixa a artéria carótida externa se origina a partir do terceiro arco aórtico (BERGMAN et al., 1998; DRAKE; VOGL; MITCHELL, 2005a,b). Se a artéria carótida externa origina-se próximo ao saco aórtico, o nível da bifurcação carotídea aparece baixo, pelo contrário, se a artéria carótida externa origina-se no topo do terceiro arco aórtico ou originar diretamente da aorta dorsal, a bifurcação carotídea aparece alta. Além disso, o desenvolvimento da artéria carótida interna a partir do segundo arco aórtico e partes da aorta dorsal com simultânea formação da artéria carótida externa a partir de pequenos canais obtidos por obliteração do primeiro arco aórtico pode mudar a posição da bifurcação carotídea para mais alta (SADLER, 1990). A posição muito alta da bifurcação carotídea (no crânio) ou o crescimento desproporcional de alguns segmentos da árvore carotídea poderiam explicar as observações de bifurcações carotídeas não encontradas em alguns casos.

No entanto, Klosek e Rungruang (2008) afirmaram que vale ressaltar que níveis das vértebras cervicais mostraram diferenças entre os gêneros e entre os lados do mesmo indivíduo.

Ord e Ward-Booth (1986) observaram a bifurcação carotídea no nível da cartilagem cricóide, $4 \mathrm{~cm}$ acima da clavícula.

Vitek e Reaves (1973) relataram bifurcação carotídea tão baixa quanto o nível da vértebra T3.

Alguns autores relataram casos de não bifurcação da artéria carótida comum na literatura (KANEKO et al., 1996; ROBERTS; GERALD, 1978; TRIGAUX; 
DELCHAMBRE; VAN BEERS, 1990). Um nível assimétrico da bifurcação em relação aos lados direito e esquerdo, é frequentemente observada, sendo que o lado esquerdo mais para cranial em relação ao lado direito em 50\% dos casos (KANEKO et al., 1996; ROBERTS; GERALD, 1978; SMITH; LARSEN, 1979; TRIGAUX; DELCHAMBRE; VAN BEERS, 1990; VITEK; REAVES, 1973). Foi observada a existência da bifurcação carotídea em todos os casos do estudo realizado por Ozgur, Govsa e Ozgur (2008).

Lewis e Brooks (1999) verificaram a prevalência de radiopacidades na região da bifurcação da artéria carótida, avaliando 1.156 radiografias panorâmicas obtidas dos arquivos de pacientes da Faculdade de Odontologia de Michigan. O estudo constituiuse de 554 pacientes do gênero masculino e 602 do feminino, com idade média de 32 anos e uma variação de 7 a 95 anos de idade. Havia 175 pacientes acima de 55 anos. Esses autores, encontraram calcificações em artéria carótida em 9 pacientes, sendo 4 do gênero masculino e 5 do feminino. Todos, exceto um, tinham idade superior a 55 anos. Das calcificações em artéria carótida encontradas, 44\% eram circulares ou ovóides, 34\% eram irregulares ou angulares e 22\% eram lineares. Dentre essas lesões, 55\% apareceram em focos múltiplos. Em um desses casos, as ramificações da artéria carótida comum estavam inteiramente calcificadas, dando origem a uma aparência de bainha da artéria carótida comum, artéria facial, ramificação maxilar da artéria carótida interna e outras microvasculaturas bilateralmente. Infelizmente, esse paciente faleceu um mês após a radiografia panorâmica ter sido realizada.

Nas radiografias panorâmicas, os ateromas calcificados localizam-se posterior e inferiormente ao ângulo da mandíbula, num ângulo de aproximadamente $45^{\circ}$. Essas radiopacidades estão separadas e distintas do osso hióide e, variavelmente, aparecem 
acima ou abaixo desse. Podem aparecer como uma massa radiopaca nodular, ou como duas linhas radiopacas verticais dentro das paredes da artéria, no nível da margem inferior da terceira vértebra cervical (FRIEDLANDER; FRIEDLANDER, 1998). Lewis e Brooks (1999) acrescentam que a aparência típica do ateroma calcificado de carótida é de uma ou mais massas nodulares radiopacas adjacentes, mas não contíguas, às terceira e quarta vértebras cervicais. A bifurcação da carótida, local usual das calcificações, pode estar localizada mais abaixo em alguns pacientes.

De acordo com Carter (2000), o cirurgião-dentista deverá ser capaz de diferenciar os ateromas calcificados da artéria carótida das radiopacidades anatômicas e patológicas localizadas na região cervical. Dentre essas estruturas estão o osso hióide, a epiglote e os ligamentos estilomandibular e estilohioídeo.

Friedlander, Dounis e Gratt (1996) afirmaram que as radiografias cefalométricas laterais convencionais também abrangem a região da bifurcação da artéria carótida, mas uma revisão da literatura médica e odontológica é falha para descobrir quaisquer relatos que tratam com a eficácia destas radiografias na detecção dos ateromas calcificados de artéria carótida. Assim, esses autores realizaram um estudo para determinar se essas lesões calcificadas poderiam ser detectadas por meio de radiografias cefalométricas laterais convencionais. Foram analisadas 1063 radiografias cefalométricas laterais de adultos saudáveis do sexo masculino com idades entre 25 a 85 anos. Aproximadamente $2 \%$ dessas pessoas tinham lesões, as quais estavam no nível da terceira e quarta vértebra cervical e estavam sobrepostos a estas estruturas, à fascia pré-vertebral e ao espaço aéreo faríngeo. Com base nos achados, eles 
concluíram que a radiografia cefalométrica lateral pode demonstrar calcificações consistentes com aterosclerose de artéria carótida.

Friedlander (1995) utilizou radiografias ântero-posteriores de coluna cervical para confirmar a presença e a localização ateromas calcificados de artéria carótida, quando observados em radiografias panorâmicas. Porém, em dois casos, as radiografias ântero-posteriores de coluna cervical demonstraram ateromas calcificados de artéria carótida bilaterais, enquanto que as radiografias panorâmicas somente unilaterais.

A divulgação das informações a respeito dos ateromas calcificados em artéria carótida em revistas odontológicas, e a própria importância do curso clínico da doença, com conseqüências muitas vezes dramáticas para o paciente, provocou um modismo entre os profissionais, de forma que toda e qualquer calcificação observada na área topográfica correspondente à bifurcação de carótida nas radiografias panorâmicas acabasse sendo apontada como ateroma calcificado. Em muitas situações o paciente mostra-se apreensivo em decorrência da preocupação desencadeada por tal suspeita, motivando maiores danos pelo fator emocional do que propriamente pela moléstia da qual eventualmente possa ser portador, segundo Kamikawa et al. (2006).

\subsection{Sialólitos em glândula submandibular}

A sialolitíase é uma disfunção comum das glândulas salivares e é causada pela formação de sialólitos. Os sialólitos são concreções calcificadas que se desenvolvem no sistema de ductos intra ou extraglandular e se formam como um resultado da 
mineralização de detritos que se acumularam no lúmen do ducto. Essas concreções ocorrem com maior frequência nos ductos salivares, do que dentro das glândulas (LUSTMANN; REGEV; MELAMED,1990). As obstruções das secreções salivares por sialólitos podem resultar em dor e edema, ou ainda, infecção na glândula. O edema é normalmente correlacionado a refeição, quando a secreção salivar está aumentada (LEVY; REMINE; DEVINE, 1962; NEW; HARPER, 1931; RAUCH; GORLIN, 1970).

Estima-se que a sialolitíase afeta 12 de cada 1000 pacientes na população adulta (LEUNG; CHOI; WAGNER, 1999).

Os cálculos salivares ocorrem em $92 \%$ dos casos na glândula submandibular, $6 \%$ dos casos na glândula parótida e $2 \%$ dos casos em ambas as glândulas salivares sublingual e menores. Podem ocorrer em todas as idades, porém o pico de incidência está na quarta, quinta e sexta décadas de vida, segundo Lustmann, Regev e Melamed (1990). Na maioria dos casos, (70\%-80\%) um sialólito é encontrado, 2 sialólitos em aproximadamente $20 \%$ dos casos, e 3 ou mais sialólitos em aproximadamente $5 \%$ dos pacientes (LEVY; REMINE; DEVINE, 1962; RAUCH; GORLIN, 1970).

Muitas teorias têm sido apresentadas para explicar a formação de cálculos salivares, tais como calcificação em torno de corpos estranhos, células epiteliais descamadas e microorganismos nos ductos (LUSTMANN; SHTEYER, 1981; RAUCH; GORLIN, 1970).

A alta incidência de cálculos submandibulares podem ser explicados pelo $\mathrm{pH}, \mathrm{o}$ conteúdo de mucina e alta concentração de cálcio nesta glândula. O comprimento e o trajeto ao redor do músculo milo-hióideo e a secreção contra a gravidade podem também contribuir para essa predileção (RAUCH; GORLIN, 1970). 
Williams (1999), afirmou que os cálculos salivares clinicamente são arredondados ou ovais, ásperos ou lisos e de coloração amarelada. Eles são constituídos principalmente de fosfato de cálcio com quantidades menores de carbonatos, na forma de hidroxiapatita, com quantidades menores de magnésio, potássio e amônia. Essa mistura está distribuída uniformemente em toda parte. Os cálculos submandibulares são 82\% inorgânicos e 18\% de material orgânico, enquanto que cálculos da glândula parótida são compostos de $49 \%$ de material inorgânico e 51\% orgânico. O material orgânico é composto de diversos carboidratos e aminoácidos. Elementos bacterianos não têm sido identificados no centro de um sialólito.

Seward (1968) citou que os cálculos salivares podem ser encontrados anteriormente no ducto da glândula submandibular, posteriormente na parte extraglandular do ducto, ou na parte intraglandular da porção principal da glândula. Os cálculos anteriores são aqueles que se encontram anteriormente à linha de união da superfície mesial dos segundos molares. No interior da glândula submandibular, o ducto principal faz uma curva fechada descendente; os cálculos salivares que se encontram na região da curva fechada no ducto são intraglandulares. Os cálculos salivares normalmente assumem a forma do ducto. Assim, cálculos desenvolvidos dentro do lúmen na parte anterior do ducto da glândula submandibular tendem a ser pequenos alongados e cilíndricos, assumindo uma configuração intraluminal do ducto. Por outro lado, os cálculos que se desenvolvem no segmento posterior da parte extraglandular do ducto ou na parte intraglandular são mais irregulares e tendem a ser maiores.

De acordo com Waite (1969), de $75 \%$ a $85 \%$ de todos os cálculos salivares, ocorrem na glândula submandibular e $20 \%$ podem ser não radiopacos. 
Segundo Blair (1973) e Yune e Klatte (1972), os cálculos salivares podem ser invisíveis em radiografias padrões ou radiografias de baixa densidade. Entretanto, essas radiografias, juntamente com a história do paciente e sintomas e exame clínico cuidadoso, podem ser suficientes para auxiliar no diagnóstico da presença de cálculo radiopaco na glândula salivar. Embora o termo cálculo represente uma concreção composta de sais minerais, esses autores utilizaram esse termo para se referirem às massas parcialmente calcificadas ou não calcificadas as quais são radiolúcidas. O sialograma é útil para confirmar se a massa calcificada é, realmente, um sialólito, e não um problema extraductal ou extraglandular.

Langlais e Kasle (1975) descreveram que os sialólitos radioluscentes e estenoses dos ductos mimetizam sialolitíases e podem ser observadas somente por sialografia.

Os sialólitos pouco calcificados (cálculos radiolúcidos) não podem ser vistos por meio de radiografias, tornando o diagnóstico mais complicado. Sialografia ou ultrassom devem ser utilizados no diagnóstico de sialólitos não radiopacos (GRÜNEBAUM; ZIV; MANKUTA, 1985; LUYK; DOYLE; FERGUSON, 1991; WITTICH; SCHEIBLE; HAJEK, 1985).

Segundo Bodner (1993), os métodos de imagem para localização de sialólito geralmente disponíveis incluem: radiografia plana, sialografia, tomografia computadorizada, ultrassom e cintilografia. A função das radiografias no diagnóstico de sialolitíase é bem reconhecida com um índice de descoberta de 80-90\% (LEVY; REMINE; DEVINE, 1962; LUSTMAN; REGEV; MELAMED, 1990).

Geralmente, as técnicas radiográficas mais comuns para diagnosticar sialólitos são a panorâmica e a oclusal (LANGLAIS; LANGLAND; NORTJÉ, 1995). 
A ultra-sonografia é a primeira linha de investigação na avaliação da sialolitíase devido a sua alta sensibilidade e especificidade, segundo Alyas et al. (2005).

Sialólitos são bem observados em radiografias periapicais e panorâmicas, mas podem estar pouco visíveis pela sobreposição das raízes dos dentes molares e prémolares e inserção muscular na cortical da mandíbula. Um cálculo intraductal de dimensão grande, normalmente será observado como uma calcificação anteriormente inclinada devido ao curso ascendente do ducto pela curvatura na fossa lingual ao assoalho anterior da boca. Tanto as pequenas calcificações e por vezes os grandes sialólitos podem ser assintomáticos e podem aparecer como achados radiográficos, segundo Graziani et al. (2006).

Segundo Huang et al. (2009), outras técnicas de imagens que podem ser usadas para o diagnóstico de sialólitos incluem a sialografia, a ultrassonografia, tomografia computadorizada e a sialografia por ressonância magnética. A sialografia raramente é indicada e deve ser restrita aos casos com suspeita de estreitamento ou outra obstrução ductal, mas sem uma calcificação visível na imagem de rotina. A ultrassonografia irá localizar um sialólito, mas, com a posterior observação na imagem convencional, e é de utilização clínica limitada e, na maioria dos casos, introduz um passo desnecessário na sequência do diagnóstico. É prudente considerar e excluir a presença de múltiplos sialólitos em qualquer paciente que se apresentam com um sialólito. Estes podem ser localizados em um ou ambos o ducto e a glândula. A tomografia computadorizada é útil em qualquer situação em que existem vários sialólitos ou quando o sialólito está situado em um local não facilmente examinado intraoralmente, por exemplo, a fossa lingual e proximalmente incluindo calcificações intraglandulares e igualmente para a glândula parótida. 
É importante distinguir sialólitos de outras estruturas que podem sofrer calcificações, além da glândula salivar e deve-se levar consideração no diagnóstico diferencial toro mandibular, osteoma, calcificações em linfonodos, flebólitos e outras calcificações vasculares, placas ateroscleróticas calcificadas em vasos sangüíneos maiores, entre outros (BAR et al., 2007; MANDEL, 2006).

Suarez-Cunqueiro et al. (2002) afirmaram que uma calcificação em uma pequena secção da artéria facial próximo a área submandibular poderia simular um sialólito. A calcificação na artéria carótida comum geralmente está localizado próximo às vértebras C3, C4 e mais lateralmente em uma visão panorâmica do que um sialólito (PORNPRASERTSUK-DAMRONGSRI; THANAKUN, 2006).

\subsection{Calcificações das cartilagens tireóideas, tritíceas e a epiglote}

Os elementos de suporte da laringe são compostos por cartilagens. Nove são as cartilagens da laringe: tireóide, cricóide e epiglote (ímpares); aritenóide, cuneiforme e corniculada (pares). Além disso, o osso hióide está intimamente relacionado funcionalmente ao esqueleto da laringe (GRAY, 1918).

As cartilagens tireóidea, cricóidea e aritenóidea são do tipo hialina e a epiglote, corniculada, cuneiforme e o ápice da aritenóide são do tipo elástica. Com a idade, as cartilagens elásticas têm pequena tendência para calcificação, mas não ossificação, no entanto, as cartilagens hialinas tornam-se mais ou menos ossificadas, segundo Milroy (1992). 
A cartilagem tireóidea sofre ossificação endocondral com o passar do tempo.

Em uma investigação realizada por Jurik (1984), em 64 pacientes (48 homens, 16 mulheres) acima de 34 anos, o grau e frequência de ossificação da cartilagem tireóide foram menores nas mulheres do que nos homens, especialmente quanto a parte anterior da cartilagem. Calcificações das cartilagens tireóidea e cricóidea foram mais marcadas e mais frequentes nas mulheres do que nos homens. Nas cartilagens hialinas da laringe, a calcificação nem sempre precede a ossificação e existe pouca correlação entre as duas.

Os fenômenos de calcificação e ossificação devem ser diferenciados. Independentemente dos raros casos de verdadeira infiltração calcária, o cálcio deposita-se geralmente em zonas previamente alteradas por outras causas. Esse fato é apoiado pelas várias descrições patológicas de calcificações de partes necróticas de vários órgãos. O fenômeno é mais observado após os sessenta anos de idade, segundo Dedivitis et al. (2001). Na maior parte dos casos, a deposição ocorre na substância fundamental onde é mais intensa a morte de muitas células. Já a ossificação é mais freqüente no sexo masculino e após os quarenta anos de idade. A zona ossificada apresenta a estrutura de típico osso lamelar. O osso é sempre delimitado por um halo de cartilagem, nunca havendo uma zona de transição, o que confirma que o processo é de substituição (AMPRINO; BAIRATI, 1933).

Mupparapu e Vuppalapati (2005) realizaram em estudo para identificar as variações na ossificação fisiológica das cartilagens laríngeas humanas pela avaliação das radiografias cefalométricas laterais de homens e mulheres saudáveis, com idades variando de 10 a 59 anos. Esses autores concluíram que radiograficamente, a ossificação das cartilagens cricóidea e tireóidea foi em geral inexistente antes da 
segunda década. A ossificação das cartilagens cricóideas e tireóideas variou de sombras lineares para densas calcificações laminares em pacientes que estavam na terceira década ou mais. A ossificação das cartilagens tireóideas e cricóideas aumentaram progressivamente com a idade em ambos os sexos. Se uma tendência para ossificação da tireóidea ou cricóidea é notada em uma idade muito precoce, o paciente deve ser examinado para sinais sugestivos de calcificação metastática incluindo calcificações em outras estruturas, como a articulação atlanto-occipital, glândula pineal, foice cerebral, etc. Assim o encaminhamento a um médico pode ser necessário para um minucioso exame físico. A ossificação fisiológica deve ser considerada uma variação na ausência de características clínicas indicativas de anormalidade sistêmica subjacente (MUPPARAPU; VUPPALAPATI, 2002).

Salman e Kinney (1990) relataram um caso de uma paciente de origem hispânica que foi encaminhada para avaliação protética. Na radiografia cefalométrica, observouse uma radiopacidade homogênea bem delimitada consistente com uma cartilagem tireóide calcificada. A história médica da paciente não contribuía, e os resultados do exame físico foram negativos. Nenhum exame complementar foi realizado.

Carter (2000) afirma ainda que, o corno superior de uma cartilagem tireóide calcificada é representado na radiografia panorâmica como uma calcificação de tecido mole vertical de aproximadamente $4 \mathrm{~mm}$ de largura e $15 \mathrm{~mm}$ de comprimento, medial à imagem de C4 superposta ao tecido mole pré-vertebral. Geralmente, somente a porção superior (2 a $3 \mathrm{~mm}$ ) dessa cartilagem calcificada será visível na borda inferior da radiografia panorâmica. Somente se o chassi for posicionado além do limite inferior, será observado um comprimento maior dessa cartilagem. 
Carter (2000) relatou que muitos profissionais não estão cientes que uma cartilagem tritícea calcificada, ou menos freqüentemente o corno superior de uma cartilagem tireóide calcificada, podem ser confundidos com placa arterial calcificada. As pequenas cartilagens tritíceas pareadas são encontradas centralmente dentro da borda livre posterior dos ligamentos tireo-hióideos laterais. Essas radiopacidades ovóides com aproximadamente 2 a $4 \mathrm{~mm}$ de largura e 7 a $9 \mathrm{~mm}$ no comprimento, são comumente descritas dentro do espaço aéreo faríngeo adjacente a porção posterior do C4 (HATELY; EVISON; SAMUEL, 1965). A palavra tritícea vem do Latim triticeus, significa semelhante a grãos de trigo (TAYLOR, 1988).

As cartilagens tritíceas são estruturas bilaterais ovóides que fazem parte de um complexo de estruturas encontradas na área do esqueleto da laringe (AJMANI; JAIN; SAXENA, 1980; CARTER, 2000; GROSSMAN, 1945). A cartilagem tritícea está centralmente localizada no ligamento tireo-hióideo lateral ao nível das terceira e quarta vértebras cervicais (C3-C4). Clinicamente, cartilagem tritícea não tem nenhuma função conhecida, embora recentemente tenha sido sugerido que poderia ajudar a reforçar os ligamentos tireo-hióideos laterais (CARTER, 2000). Quando calcificada, a cartilagem tritícea pode ser facilmente observada em uma radiografia panorâmica e pode ser diagnosticada como uma calcificação na artéria carótida ou outras calcificações distróficas do tecido mole. A cartilagem tritícea pode ser diagnosticada como um ateroma de carótida calcificada, devido à sua localização em uma radiografia panorâmica. Os ateromas carotídeos calcificados são um fator de risco para acidente vascular cerebral, assim, os clínicos têm a necessidade de distinguir entre uma cartilagem tritícea e um ateroma de carótida calcificada. 
Ahmad, Madden e Perez (2005) realizaram um estudo cujo objetivo foi determinar a prevalência cartilagem tritícea calcificada em radiografias panorâmicas, a distribuição entre idade e gênero e também para identificar se a forma da cartilagem tritícea difere do ateroma carotídeo. Esses autores afirmaram que embora cartilagens tritíceas e ateromas carotídeos calcificados estejam localizados em uma região semelhante nas radiografias panorâmicas, a forma e contorno podem ajudar diferenciar estas duas calcificações no pescoço. A cartilagem tritícea é especificamente localizada entre ao corno maior do osso hióide e o corno superior da tireóide, enquanto que a localização do ateroma carotídeo calcificado não está limitada pelo osso hióide ou tireóide. Em uma radiografia panorâmica, a cartilagem tritícea também pode ser confirmada pela sua localização, situada em uma linha imaginária que une o corno maior do osso hióide e ao corno superior da cartilagem tireóidea. Esta linha imaginária geralmente é reta, mas ocasionalmente podem seguir uma ligeira curvatura. Foi encontrado que os indivíduos na faixa etária de 51 a 60 anos tinham prevalência significativamente maior de cartilagem tritícea calcificada comparada a outros grupos etários. Este estudo mostrou que a calcificação é mais comum no sexo feminino. Este achado é provavelmente devido a um maior número de indivíduos do sexo feminino nesta faixa etária, no presente estudo. Também não encontraram qualquer diferença estatística significativa nos tamanhos entre ateromas carotídeos calcificados e as cartilagens tritíceas calcificadas. Assim, concluíram que a diferença de tamanho dos ateromas carotídeos calcificados e das cartilagens tritíceas calcificadas não é um critério confiável para a diferenciação entre estas entidades. Ahmad, Madden e Perez (2005) demonstraram ainda que a forma da cartilagem tritícea é em grande parte oval 
bem definida. As margens da cartilagem tritícea eram lisas, enquanto grandes ateromas carotídeos calcificados tinham margens irregulares.

O estudo anterior mostrou que ateromas carotídeos calcificados eram na sua maioria circulares quando pequenos, e quando as calcificações ampliavam em tamanho, tornavam-se predominantemente linear ou fino retangular (AHMAD; MADDEN; EL-ASHIRY, 2002). No estudo de 2005, mostrou semelhante tendência na forma das calcificações da carótida. Os ateromas carotídeos calcificados revelaram áreas de discreta radioluscências, enquanto que a cartilagem tritícea calcificada tinha radiodensidade uniforme.

Os resultados do estudo realizado por Ahmad, Madden e Perez (2005) indicam que a forma, contorno e a localização ajudam a discriminar a cartilagem tritícea calcificada da calcificação em artérias carótidas.

Em um estudo realizado por Ajmani, Jain e Saxena (1980) em cadáveres de adultos provenientes da Índia, a cartilagem tritícea calcificada foi mais comumente encontrada no gênero feminino (9,5\%) em comparação aos homens $(7,3 \%)$.

Ajmani (1990) em um estudo feito em cadáveres nigerianos adultos, a calcificação da cartilagem tritícea foi mais prevalente no gênero feminino $(16,7 \%)$ quando comparado ao masculino (13,2\%).

Um estudo realizado por Hately, Evison e Samuel (1965) utilizando radiografia de pescoço mostrou uma maior prevalência de calcificação da cartilagem tritícea no gênero masculino (29\%) quando comparado ao feminino (22\%).

Um estudo realizado por O'Bannon e Grunow (1954) também havia mostrado que a calcificação da cartilagem tritícea era mais comum no gênero feminino.

Hately, Evison e Samuel (1965) relataram a incidência mais cedo da cartilagem tritícea calcificada na idade de 23 anos. 
Um achado foi relatado por Yerman, Werkhaven e Schild (1988), que mostraram que não houve nenhuma correlação entre o aumento da calcificação das cartilagens laríngeas com a idade avançada.

A epiglote é uma pequena cartilagem em forma de folha que se projeta ascendentemente por detrás da língua e osso hióide (LAUFER, 1981). Durante a deglutição, a epiglote é bem conhecida por impedir a entrada de alimentos ou líquidos à traquéia. A importância das suas funções mecânica e dinâmica é devido à flexibilidade da cartilagem elástica que forma a sua estrutura e pelas conexões ligamentares e musculares aos órgãos adjacentes (MAFEE, 1984).

A calcificação ou ossificação da cartilagem epiglótica atinge sua propriedade mecânica. A cartilagem epiglótica tem sido considerada uma cartilagem permanente que não sofre ossificação (AJMANI; JAIN; SAXENA, 1980).

Kano et al. (2005) realizaram uma investigação morfométrica da cartilagem epiglótica por meio de macroscopias e microscopias ópticas utilizando uma técnica histológica digitalizada. As alterações estruturais da cartilagem epiglótica foram discutidas em relação à idade e sexo. O volume dos depósitos de cálcio na área foi maior no sexo masculino do que no feminino e foi significativamente aumentado no grupo de pacientes com idade variando de 80 a 98 anos de idade no sexo masculino. 0 nível inferior da cartilagem epiglótica apresentou uma maior deposição de cálcio do que a área do nível superior. A cartilagem epiglótica exibiu acentuada diferença significativa relacionada ao gênero e progressão da calcificação com a idade. A calcificação da cartilagem epiglótica em pacientes mais idosos pode afetar o padrão de movimento da deglutição. 


\subsection{Tonsilolitos}

Tonsilolitos ou cálculos tonsilares são estruturas calcificadas que se desenvolvem em criptas tonsilares maiores que estão envoltos por bactérias e debris orgânicos (NEVILLE et al., 2002). Aspestrand e Kolbenstvedt (1987) relataram que quando revisaram cortes axiais de TC de cabeça e pescoço, encontraram tonsilolitos assintomáticos medindo de 1 a $7 \mathrm{~mm}$ em $16 \%$ dos cortes.

$\mathrm{Na}$ opinião de muitos investigadores, pequenas calcificações nas tonsilas palatinas podem freqüentemente ser encontradas quando as tonsilas são seccionadas e análises forem feitas ao microscópio (REVEL et al., 1998). Contudo, exame físico ou radiografia convencional podem não ser suficientes para diagnosticar os tonsilolitos, segundo Aspestrand e Kolbenstvedt (1987).

A patogênese dos tonsilolitos não está completamente conhecida. O exame microscópico dos tonsilolitos mostra que eles são compostos de fosfato, cálcio, carbonato e magnésio, com uma mistura de material orgânico, incluindo debris epiteliais e bactérias (COOPER et al., 1983). Muitos investigadores têm sugerido que tonsilolitos originam-se com resultado de inflamação tonsilar recorrente (RAM et al., 2004). Entretanto, essa origem não explicaria a existência de cálculos em áreas peritonsilares. Dois outros mecanismos são propostos. Um deles é que abscessos peritonsilares podem calcificar (WESTMORE; HUPP, 1988) e outro que os cálculos podem desenvolver-se secundariamente a estase salivar dentro de glândulas salivares menores da região palatal, segundo Silvestre-Donat et al. (2005). 
Suarez-Cunqueiro et al. (2008) relataram o primeiro caso de múltiplas calcificações em tonsilas palatinas, em associação a um sialólito na glândula submandibular em um homem de 42 anos de idade. Esta associação foi previamente relatada (COOPER et al., 1983; GIUDICE et al., 2005) que parece sugerir que ambas as condições podem ter mecanismos patogênicos comuns. Assim, tonsilolitos podem estar relacionados à litíase nas outras regiões tais como as glândulas submandibulares (COOPER et al., 1983).

O diagnóstico diferencial de tonsilolitos deve ser realizado para cálculos na parótida, calcificações em linfonodos, granuloma calcificado, corpo estranho nas tonsilas, processo estilóide alongado, calcificação do ligamento estilohióideo, calcificação da artéria carótida e um flebólito (SUAREZ-CUNQUEIRO et al., 2002). No entanto, esses autores estão de acordo com outros investigadores em que só uma análise cuidadosa por tomografia computadorizada mostra a verdadeira natureza destas estruturas (ASPESTRAND; KOLBENSTVEDT, 1987).

Os tonsilolitos ocorrem mais freqüentemente em adultos do que em crianças. Cooper et al. (1983) revisaram 23 casos de tonsilolitos e encontraram que os pacientes tinham uma faixa etária de 20 a 68 anos, sem predileção por gênero. O tonsilolito varia de consistência mole e friável a dura como pedra, e os depósitos podem ser únicos ou múltiplos.Os tonsilolitos surgem a partir de material retido e crescimento bacteriano em criptas tonsilar ou adenoideano e ocorrem em pacientes com ou sem história de doenças inflamatórias quer das tonsilas ou adenóides (GERALD, 1985; REVEL et al., 1998). Algumas vezes os tonsilolitos podem causar sintomas, incluindo dor de garganta crônica inespecífica, tosse, disfagia, otalgia, halitose crônica; uma sensação de corpo estranho ou falta de paladar (COOPER et al., 1983). Pode ser relatado 
ataques recorrentes de tonsilites. Na ocasião um grande tonsilolito pode ulcerar até a fossa supratonsilar ou sob o pilar anterior (GERALD, 1985). Pacientes com tonsilolitos também podem ser assintomáticos, com suas lesões descobertas incidentalmente por meio de panorâmicas ou radiografias laterais faríngeas (KORNBLUT, 1991; SHETTY; LAKHKAR; SHETTY, 2001). Sobreposição de estruturas duras e tecidos moles em imagens radiográficas são comuns nesta região anatômica, criando desafios na interpretação. Muitas vezes, essa dificuldade pode ser superada pela utilização de tomografia computadorizada. No entanto, um hâmulo proeminente, um processo estilóide alongado, uma calcificação do ligamento estilohióideo, ou proeminência não usual da tuberosidade da maxila podem simular cálculos tonsilares quando apenas uma secção de tomografia computadorizada é avaliada. Exame de varreduras sucessivas tipicamente revela a verdadeira natureza destas estruturas (ASPESTRAND; KOLBENSTVEDT, 1987; REVEL, et al.,1998).

No exame clínico, o tonsilolito pode aparecer como um objeto duro branco ou amarelado dentro da cripta tonsilar, tornando o diagnóstico bastante óbvio. Contudo, em alguns casos o tonsilolito pode estar situado mais profundamente, produzindo um alargamento das tonsilas ou uma sensação de endurecimento à palpação, segundo Gerald (1985).

Segundo Pruet e Duplan (1987) as calcificações tonsilares ou tonsilolitos são relatados como sendo encontrados comumente na prática clínica diária e com pouca significância clínica. Eles adquirem importância; no entanto, se a sua apresentação é de tal ordem que pode ser interpretado como outras lesões, incluindo neoplasias malignas. Os tonsilolitos são facilmente mal interpretados em radiografias panorâmicas porque se observa sombras radiopacas sobre a porção média do ramo da mandíbula. 
Portanto, para Neshat, Penna e Shah (2001) deve-se considerar a tonsilolitíase no diagnóstico diferencial de lesões radiopacas nesta região.

Özcan et al. (2006) relataram um caso de um achado incidental de tonsilolitos bilaterais em uma paciente de 38 anos de idade, assintomática. A radiografia panorâmica revelou sombras radiopacas distintas ao longo dos ramos da mandíbula bilateralmente. Estas radiopacidades foram localizadas nas regiões de tonsilas palatinas por meio de tomografia computadorizada.

Weller (1924) relatou que durante exame histológico de rotina de tonsilas excisadas, os tonsilolitos microscópicos foram encontrados em $8 \%$ dos espécimes. Os cálculos macroscópicos, os quais o tamanho variou de pouco visível ao tamanho de uma ervilha, representaram uma forma intermediária e foram identificados em $2 \%$ das tonsilas excisadas.

Mandel (2008) relatou um caso de múltiplos tonsilolitos macroscópicos bilaterais e assintomáticos, os quais foram encontrados durante um exame radiográfico panorâmico de rotina. Para esse autor o diagnóstico diferencial de tonsilolitos pode ser feito com calcificações nas glândulas parótidas, flebólitos, calcificações em linfonodos, calcificação da cadeia estilohióidea. O diagnóstico diferencial também devem incluir estruturas anatômicas, tais como, um processo estilóide alongado, ou um processo hamular proeminente. Calcificações arteriais e corpos estranhos também deverem ser considerados. Uma doença granulomatosa de tonsila que progrediu para calcificação é outra possibilidade. Esse grupo de opacidades pode ser confundido com um tonsilolito único, mas certamente não com numerosas opacidades. Segundo Mandel (2008) por meio da radiografia panorâmica não se pode esperar a localização exata das 
radiopacidades observadas. Uma investigação $3 \mathrm{D}$ é necessária. A tomografia computadorizada com cortes axiais e coronais é indicada.

\subsection{Mineralizações/Calcificações dos ligamentos estilo-hióideos e estilomandibulares}

O ligamento estilo-hióideo é uma faixa de tecido conjuntivo inserido na extremidade livre do processo estilóide, e estendendo-se até o corno menor do osso hióide. O ligamento estilomandibular é considerado um ligamento acessório da articulação têmporo-mandibular e estende-se do processo estilóide em direção ao ângulo da mandíbula. Este conjunto de estruturas pode sofrer uma variedade de alterações (como por exemplo, mudanças no trajeto do processo estilóide do temporal, que pode apresentar acentuadas curvaturas (STAFNE; GIBILISCO, 1986); no entanto, as variações mais freqüentes correspondem a mineralizações atípicas, o que torna estas estruturas de interesse da Radiologia Dentomaxilofacial.

Foi proposta por Langlais, Miles e Van Dis (1986), uma classificação da aparência radiográfica do alongamento e mineralização do complexo ligamento estilohióide mineralizado baseado em três tipos complexos - Tipo I, alongado; Tipo II, pseudoarticulado; e Tipo III, segmentado. Esses tipos são, além disso, descritos por um padrão de calcificação: contorno calcificado, parcialmente calcificado, nodular e, completamente calcificado. 
Foram analisadas 286 ortopantomografias por Ferrario et al. (1990) para estudarem a incidência de calcificação do ligamento estilo-hióideo. Todos os pacientes não tinham sintomas. A incidência total da calcificação notada foi alta, 84.4\%. O número e o comprimento das calcificações aumentaram com a idade, e não existiu relacionamento de sexo ou tamanho mandibular. O fenômeno é freqüentemente evidente bilateralmente. A variedade de resultados relatados nas referências depende dos critérios diferentes nas avaliações radiográficas e na seleção de pacientes.

Omnell, Gandhi e Omnell (1998) relataram os resultados de um estudo radiográfico longitudinal, por meio de radiografias cefalométricas, da ossificação do ligamento estilo-hióide em uma amostra de pacientes tratados para más-oclusões. Os resultados sugerem que a grande maioria dos locais ossificados nos ligamentos estilohióideos é estabelecida durante a infância e adolescência. O comprimento principal dos locais mostra claramente um aumento rápido, linear com a idade até o final da adolescência; algum aumento, além disso, é não linear e ocorre em um padrão muito mais lento. Em indivíduos jovens os locais ossificados foram predominantes na parte superior do ligamento. Com o aumento da idade, locais ossificados tornaram-se prevalentes também em outras partes do ligamento. Locais ossificados no término da parte inferior para o osso hióide foram mais comuns do que previamente relatados.

Scaf, Freitas e Loffredo (2003) realizaram um trabalho para avaliar a reprodutibilidade relacionada à presença e às medidas do alongamento e a prevalência do processo estilóide, utilizando radiografias panorâmicas. Foram utilizadas 16 radiografias de pacientes desdentados, atendidos em um período de quatro anos na Clínica de Radiologia, da Faculdade de Odontologia de Araraquara. Cento e vinte e um pacientes eram do gênero feminino e quarenta e cinco do masculino. Dois 
examinadores calibrados avaliaram as radiografias, nas quais os processos estilóides alongados foram medidos a partir da base do osso temporal à extremidade da estrutura. O processo estilóide alongado foi considerado presente quando as medidas ultrapassaram $30 \mathrm{~mm}$. O nível de concordância entre os dois examinadores quanto à presença do processo estilóide alongado foi maior do que quando eles mediram o processo estilóide alongado. A prevalência do processo estilóide alongado foi de $12,6 \%$.

Segundo Langlais, Miles e Van Dis (1986), no caso de sintomatologia dolorosa, pode-se complementar a avaliação com outras radiografias convencionais (pósteroanterior e perfil). A radiografia póstero-anterior é a mais indicada para análise da ocorrência de desvio medial do processo estilóide do osso temporal, tendendo a interpretação, neste caso, para síndrome do processo estilóide - artéria carótida. 


\section{PROPOSIÇÃO}

Avaliar a contribuição das telerradiografias nas normas lateral e frontal na identificação e localização de calcificações em tecidos moles, quando comparado com as observadas em radiografia panorâmica. 


\section{MATERIAL E MÉTODOS}

O projeto de pesquisa foi avaliado e aprovado pela Comissão de Ética em Pesquisa da Pontifícia Universidade Católica do Paraná (Anexo A) e tornado ciente pelo Comitê de Ética em Pesquisa da FOUSP (Anexo B).

\subsection{Material}

A amostra deste estudo foi composta por 27 radiografias panorâmicas, 27 telerradiografias em norma lateral e 27 telerradiografias em norma frontal, totalizando 81 radiografias, obtidas a partir de três peças anatômicas de cadáveres, conservadas em formol, constando de cabeça e pescoço, pertencente ao Departamento de Anatomia da Pontifica Universidade Católica do Paraná.

\subsection{Métodos}

Para simular as calcificações em tecidos moles nas peças anatômicas, foram confeccionadas referências radiopacas em guta percha de formato arredondado sobre uma haste pontiaguda, conforme Figura 4.1. Estas referências foram posicionadas 
unilateralmente, procurando sempre o mesmo nível da bifurcação da artéria carótida comum, nas seguintes estruturas e localizações:

- Glândula Submandibular: no terço inferior da face superficial da porção superficial da glândula submandibular no sentido ântero-posterior e súpero-inferior.

- Cartilagem tireóidea: no corno superior da cartilagem tireóidea.

- Cartilagem tritícea: sobre a cartilagem tritícea.

- Bifurcação da artéria carótida comum: no interior da bifurcação.

- Osso hióide: corno maior do osso hióide.

- Ligamento estilo-hióideo: próximo da inserção do ligamento estilo-hióideo ao corno maior do osso hióide.

- Ligamento estilomandibular: próximo da inserção do ligamento estilomandibular ao ângulo da mandíbula.

- Tonsila palatina: na região central

- Epiglote: sobre o ápice.

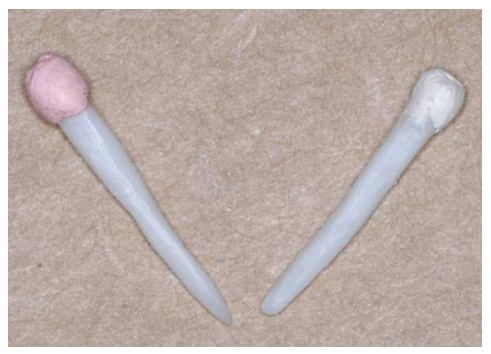

Figura 4.1 - Referência radiopaca confeccionada em guta-percha 
Para cada uma das estruturas acima citadas, foi adquirida uma radiográfica panorâmica, uma telerradiografia em norma lateral e uma em norma frontal uma totalizando assim, três incidências radiográficas para cada peça anatômica.

Para obtenção das radiografias foi utilizado o aparelho panorâmico Orthophos CD (Siemens Corp $\AA$, Munich, Germany). O regime de trabalho estabelecido foi:

-Para a peça anatômica 1: panorâmica: 60 kVp e 14 mA, com um tempo de exposição de 14 s. Telerradiografia em norma lateral: 84 kVp e 13 mA, com um tempo de exposição de 0,25 s. Telerradiografia em norma frontal: 84 kVp e 13 mA, com um tempo de exposição de 0,25s.

-Para a peça anatômica 2: panorâmica: 60 kVp e 10 mA, com um tempo de exposição de $14 \mathrm{~s}$. Telerradiografia em norma lateral: $84 \mathrm{kVp}$ e $13 \mathrm{~mA}$, com um tempo de exposição de 0,25 s. Telerradiografia em norma frontal: 84 kVp e 13 mA, com um tempo de exposição de 0,32s.

-Para a peça anatômica 3: panorâmica: 60 kVp e 14 mA, com um tempo de exposição de 14 s. Telerradiografia em norma lateral: 84 kVp e 13 mA, com um tempo de exposição de 0,25 s. Telerradiografia em norma frontal: $84 \mathrm{kVp}$ e $13 \mathrm{~mA}$, com um tempo de exposição de 0,25s.

Os filmes radiográficos empregados foram o T-Mat G/RA (Kodak®), Rochester, N.Y), tamanho $15 \times 30 \mathrm{~cm}$, com placa intensificadora Lanex (medium), de tamanho $15 \times 30$ cm (Kodak®) para a execução da radiografia panorâmica. Para a execução da telerradiografia em norma lateral e norma frontal foram utilizados os filmes T-Mat G/RA18x24 cm, com placa intensificadora Lanex (medium). Todas as radiografias foram 
processadas automaticamente com a processadora Glunz \& Jensen- Eletronic and Mechanical engeneering® modelo Multi-X 36 (Glunz \& Jensen Inc. ${ }^{\circledR}$, USA) com soluções de processamento da marca Kodak®.

Para a padronização do posicionamento da peça anatômica e estabilização da mesma no aparelho panorâmico, foi utilizado um busto de manequim confeccionado em polipropileno (Legas Metal®).

Com o objetivo de atenuar o feixe de raios $\mathrm{X}$, obtendo radiografias da peça anatômica com melhores padrões de densidade, nitidez e contraste, duas lâminas de chumbo utilizados em filmes periapicais recortadas foram adaptadas na saída do feixe de radiação, após o colimador.

Cada peça anatômica foi, então, posicionada no aparelho panorâmico sobre o busto de manequim, seguindo as orientações habituais para o posicionamento de pacientes. Assim sendo, o plano de Frankfurt foi posicionado paralelo ao plano horizontal e o plano sagital mediano perpendicular ao plano horizontal, obtendo-se assim, uma radiografia padronizada.

As telerradiografias laterais, frontais e as radiografias panorâmicas foram codificadas logo após a obtenção, e os dados de localização foram registrados em ficha própria, à qual os examinadores não tiveram acesso.

4.2.1 Avaliações das radiografias 
As radiografias foram avaliadas por 05 radiologistas odontológicos, com experiência profissional mínima de 5 anos. As avaliações foram realizadas em ambiente com luz reduzida, usando negatoscópios, sem o uso de lentes de magnificação. Para cada examinador foi entregue 09 grupos de radiografias, os quais continham 01 telerradiografia lateral, 01 frontal e 01 radiografia panorâmica. Foi solicitado que ao avaliar as 81 radiografias, respondessem a dois questionamentos em formulários conforme modelo no apêndice $A$.

01-Utilizando as telerradiografias em norma lateral e frontal e as radiografias panorâmicas, assinale qual a localização mais provável da referência radiopaca. Identifique com as letras do alfabeto utilizando as opções abaixo.
A- LIGAMENTO ESTILO-HIÓIDEO
B- BIFURCAÇÃO DA ART. CARÓTIDA
c- CORNO SUPERIOR DA CARTILAGEM TIREÓIDEA
D- EPIGLOTE
E- LIGAMENTO ESTILOMANDIBULAR
F- GLÂNDULA SUBMANDIBULAR
G- CARTILAGEM TRITÍCEA
H- CORNO MAIOR DO OSSO HIÓIDE
I- TONSILA PALATINA

02- Em sua opinião, nos casos apresentados, ao observar as imagens radiopacas nos locais sugestivos de calcificações em tecidos moles na radiografia panorâmica, as telerradiografias em norma lateral e frontal, auxiliaram no diagnóstico diferencial destas calcificações? Responda S (sim) ou N (não). 
Os dados obtidos de cada examinador foram anotados em fichas próprias, os quais foram submetidos a análise estatística.

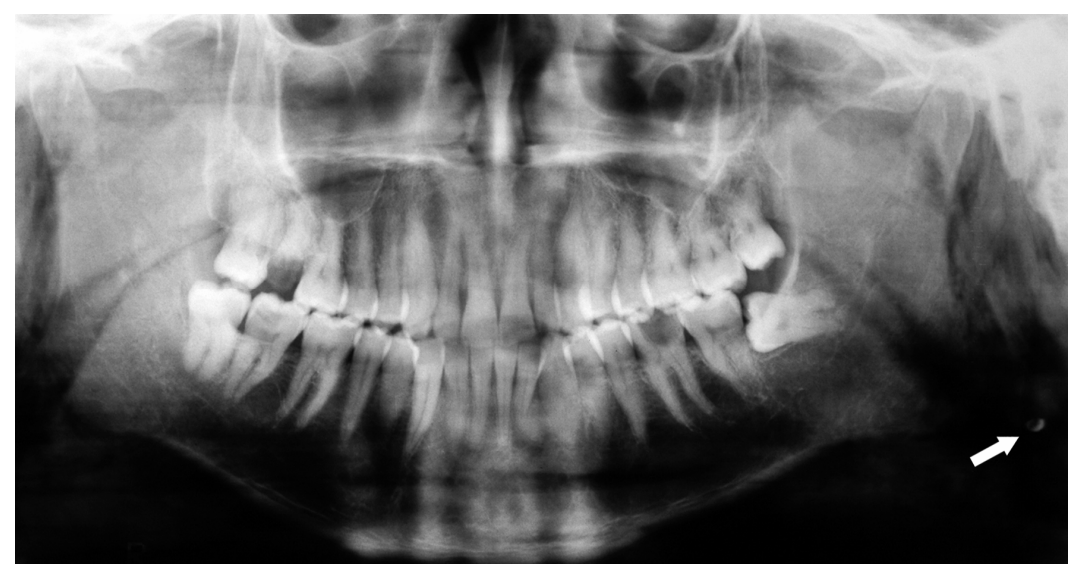

Figura 4.2 - Radiografia panorâmica -cabeça n. 03 - com referência radiopaca na cartilagem tritícea

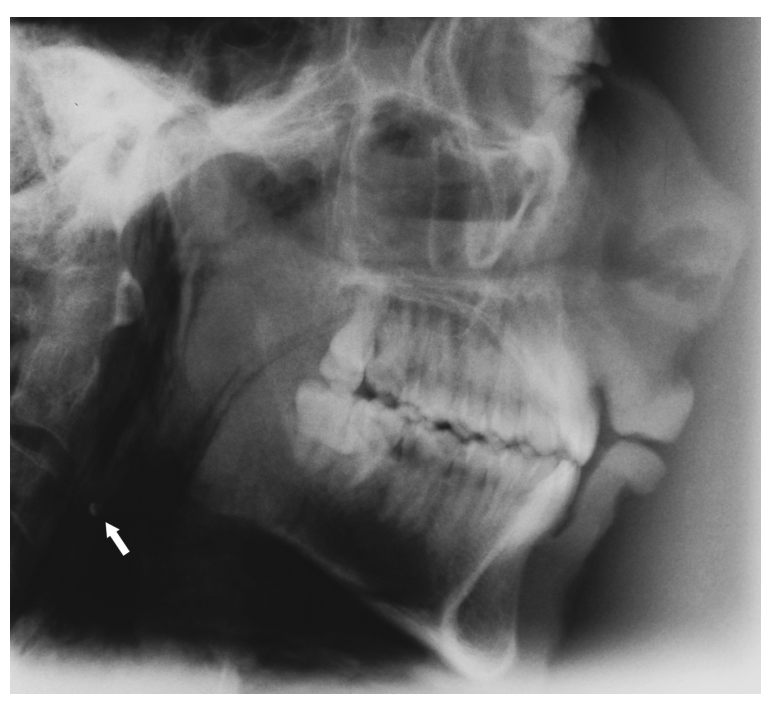

Figura 4.3 -Telerradiografia em norma lateral-cabeça n. 03 - com referência radiopaca sobre a cartilagem tritícea 


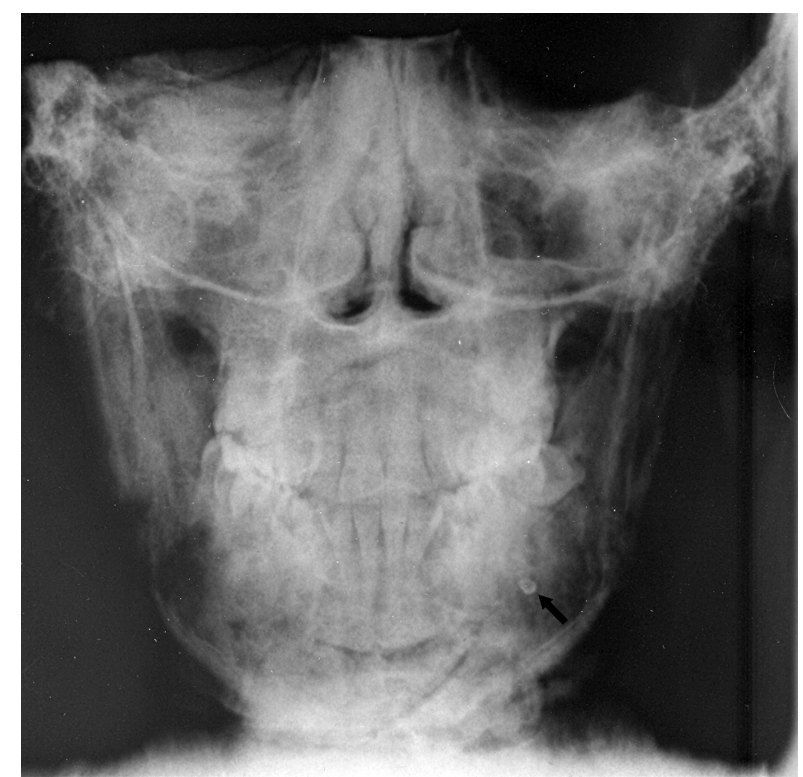

Figura 4.4 - Telerradiografia em norma frontal cabeça n. 03 - com referência radiopaca sobre a cartilagem tritícea

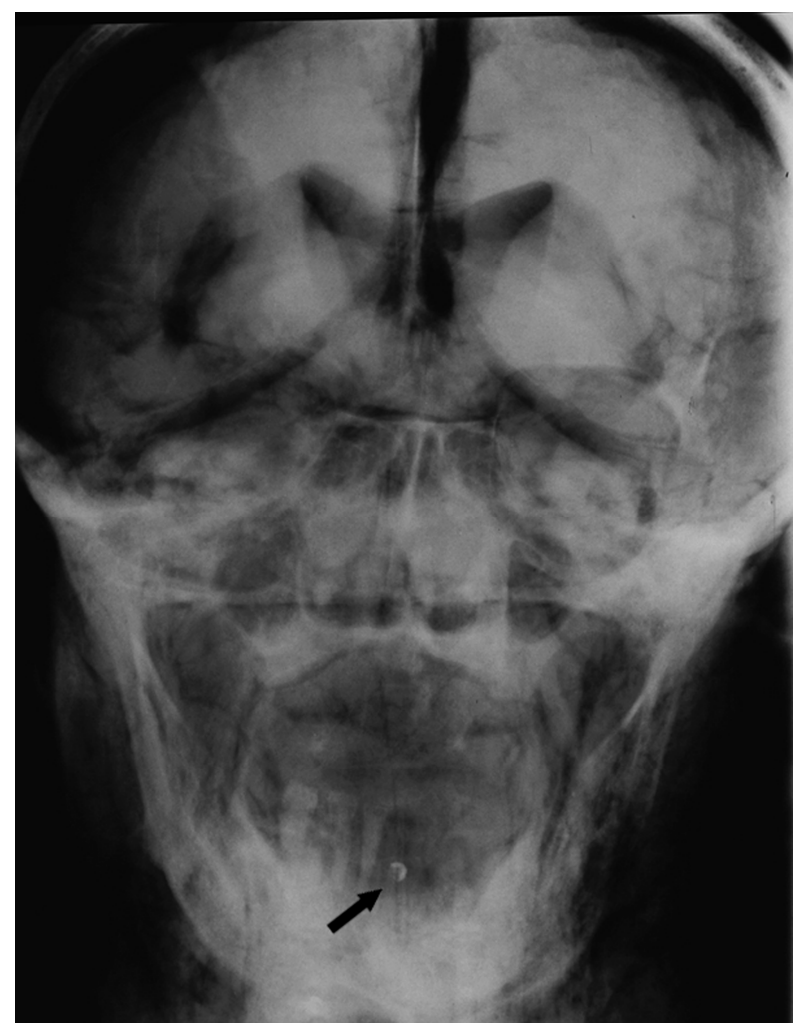

Figura 4.5 - Telerradiografia em norma frontal cabeça n. 01 - com referência radiopaca sobre a epiglote 


\subsection{Análise estatística}

Os dados coletados das observações dos examinadores foram analisados como o gráfico de correlação para análises de componentes principais e para o coeficiente de correlação intraclasse para mais de 2 examinadores com o uso do pacote estatístico "on line" da Universidade de Hong Kong (2009) ${ }^{1}$.

Utilizou-se a planilha eletrônica Excel(Microsoft) e o pacote estatístico Statistica 8.0 (StatSoft). 


\section{RESULTADOS}

Em relação ao primeiro questionamento no qual os examinadores deveriam assinalar o local mais provável da calcificação ou da estrutura anatômica utilizando as telerradiografias em norma lateral e frontal e as radiografias panorâmicas, foi realizada uma análise intraclasse de acertos entre cinco examinadores. Os resultados das observações estão ilustrados na tabela 5.1 .

\section{Cabeça 1}

A referência radiopaca que estava localizada sobre a cartilagem tritícea obteve maior percentagem de acerto (60\%) pelos examinadores. Seguido de $40 \%$ para a referência localizada no ligamento estilomandibular, tonsila palatina e epiglote. Não houve acerto nas seguintes estruturas: glândula submandibular, corno superior da cartilagem tireóidea, bifurcação da artéria carótida, corno maior do osso hióide e ligamento estilo-hióideo.

\section{Cabeça 2}

Os examinados obtiveram $60 \%$ de acerto nas radiografias em que as referências radiopacas estavam situadas na bifurcação da artéria carótida e epiglote, 40 \% na glândula submandibular, ligamento estilomandibular e tonsila palatina, 20 \% na cartilagem tritícea e ligamento estilo-hióideo. Não houve acerto nas seguintes estruturas: corno superior da cartilagem tireóidea e corno maior do osso hióide. 


\section{Cabeça 3}

As referências radiopacas que estavam localizadas sobre a cartilagem tritícea e a epiglote obtiveram maior percentagem de acerto (80\%) pelos examinadores; sobre o corno maior do osso hióide $(60 \%) ; 40 \%$ sobre a cartilagem tritícea, ligamento estilomandibular e tonsila palatina; $20 \%$ na bifurcação da artéria carótida e ligamento estilo-hióideo. Não houve acerto nas radiografias nas quais estavam as referências no corno superior da cartilagem tireóidea.

Tabela 5.1 - Freqüência de acerto pelos examinadores em avaliação de estruturas anatômicas, em cabeças de cadáveres

\begin{tabular}{c|c|c}
\hline Cabeça & $\begin{array}{c}\text { Estrutura } \\
\text { anatômica }\end{array}$ & $\begin{array}{c}\% \\
\text { acertos }\end{array}$ \\
\hline \hline \multirow{5}{*}{1} & 3 & 60 \\
& 7 & 40 \\
& 8 & 40 \\
& 9 & 40 \\
& 1 & 0 \\
& 2 & 0 \\
& 4 & 0 \\
& 5 & 0 \\
& 6 & 0 \\
\hline \multirow{5}{*}{3} & 4 & 60 \\
& 9 & 60 \\
& 1 & 40 \\
& 7 & 40 \\
& 3 & 40 \\
& 3 & 20 \\
& 2 & 20 \\
& 5 & 0 \\
\hline \multirow{5}{*}{3} & 1 & 80 \\
& 9 & 80 \\
& 5 & 60 \\
& 3 & 40 \\
& 7 & 40 \\
& 8 & 40 \\
& 4 & 20 \\
& 6 & 20 \\
& 2 & 0 \\
\hline
\end{tabular}

Os dados referem-se a \% de acertos de 5 examinadores, em relação ao controle, em 9 estruturas anatômicas e em 3 cabeças independentes. 
A tabela 5.2 refere-se à frequência individual de acertos pelos examinadores quanto à avaliação da localização da referência radiopaca sobre as estruturas anatômicas ou simulando o local da calcificação em tecidos moles, realizadas em três cabeças de cadáveres distintas, utilizando as telerradiografias em norma lateral e frontal e a radiografia panorâmica.

Os examinadores 1,2 e 5 obtiveram $22 \%$ de acerto e $78 \%$ de erro. Os examinadores 3 e 4 obtiveram $44 \%$ de acerto e $56 \%$ de erro.

Tabela 5.2 - Freqüência individual de acertos pelos examinadores em avaliação de estruturas anatômicas, em cabeças de cadáveres

\begin{tabular}{ccccc}
\hline & \multicolumn{2}{c}{$\mathrm{S}$} & \multicolumn{2}{c}{$\mathrm{N}$} \\
\cline { 2 - 5 } Examinador & $\mathrm{f}$ & $\mathrm{f}(\%)$ & $\mathrm{f}$ & $\mathrm{f}(\%)$ \\
\hline \hline 1 & 6 & 0,22 & 21 & 0,78 \\
2 & 6 & 0,22 & 21 & 0,78 \\
3 & 12 & 0,44 & 15 & 0,56 \\
4 & 12 & 0,44 & 15 & 0,56 \\
5 & 6 & 0,22 & 21 & 0,78 \\
\hline
\end{tabular}

Os dados referem-se a \% de acertos de 5 examinadores, em relação ao controle, em 9 estruturas anatômicas e em 3 cabeças independentes.

$S$ - acerto e $N$ - erro em relação ao controle; $f$ - freqüência absoluta; $f(\%)$ - frequência relativa

Tabela 5.3 - Coeficiente de correlação intraclasse em avaliação de estruturas anatômicas de cabeças de cadáveres

\begin{tabular}{lc}
\hline Exames & ICC $^{\star}$ \\
\hline \hline Total & 0,0977 \\
Cabeça 1 & 0,0075 \\
Cabeça 2 & 0,0645 \\
Cabeça 3 & 0,0977 \\
\hline
\end{tabular}

ICC - Correlação intraclasse

* Ausência de correlação entre os observadores

A tabela 5.3 refere-se aos coeficientes de correlação da intraclasse (ICC), obtidos usando o pacote estatístico "on line" da Universidade de Hong Kong (2009) 
foram: 0,0977 para todos os resultados; 0,0075 para a cabeça $1 ; 0,0645$ para a cabeça 2; 0,0977 para a cabeça 3. De acordo com os critérios de Cicchetti e Sparrow (1981), os ICC podem ser classificados para níveis de significado clínico como: ruim <0,40; razoável, 0,40 a 0,59; bom, 0,60 a 0,74; excelente, 0,75 a 1,00. Todos os ICC obtidos foram inferiores à 0,40 .

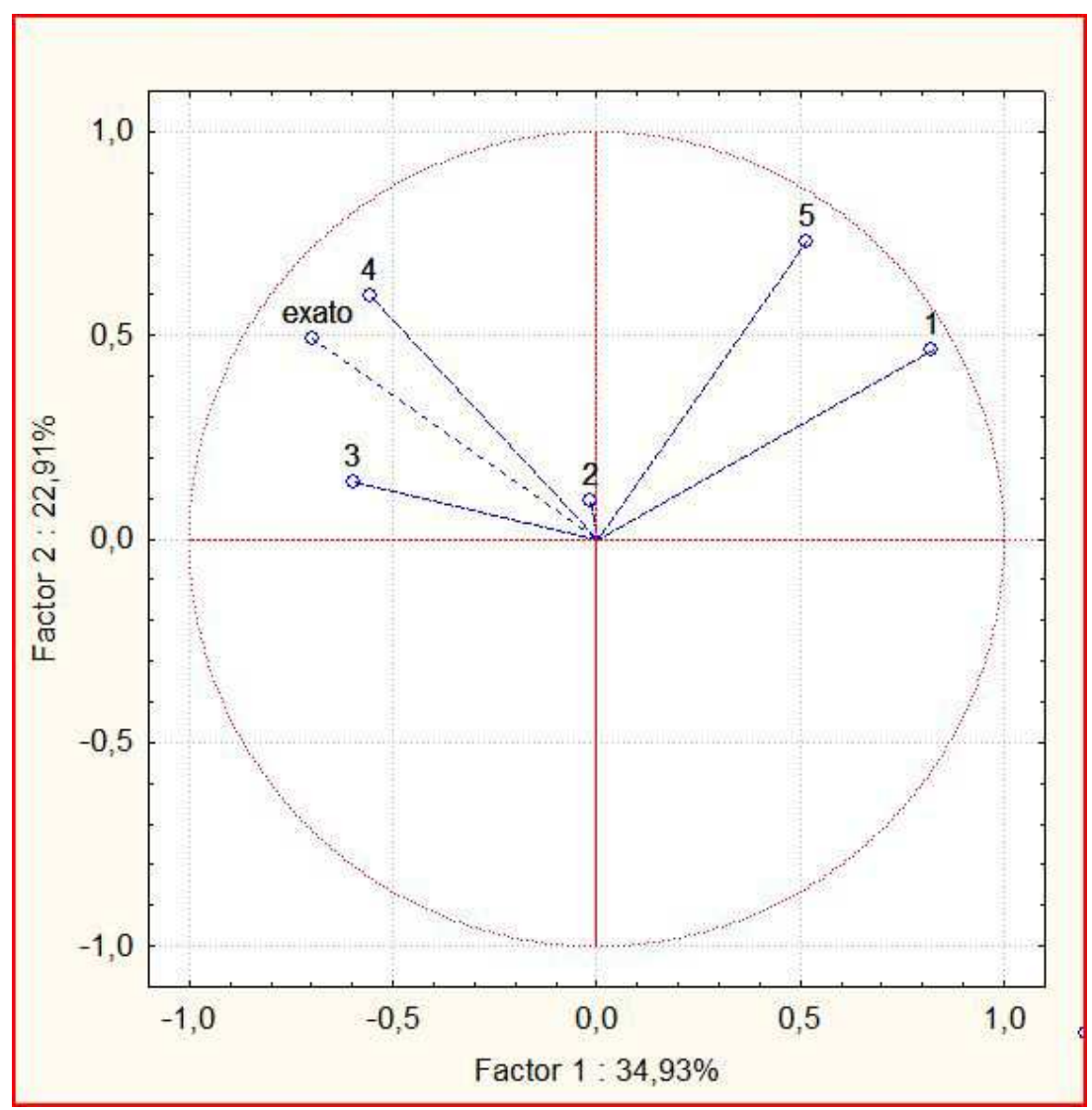

Gráfico 5.1 - Gráfico do ciclo de correlação para o fator pontuação* das variáveis na análise dos componentes principais

*Projeção dos fatores pontuação das variáveis nos planos $(1 \times 2)$ 
Tabela 5.4 - Coeficiente de correlação de Pearson para os resultados codificados em avaliação de estruturas anatômicas de cabeças de cadáveres

\begin{tabular}{cccc}
\hline Examinador vs exato & $\mathrm{R}$ & to & $\mathrm{p}$ \\
\hline \hline 3 & 0,278 & 1,446 & 0,161 \\
4 & 0,556 & 3,341 & 0,003 \\
\hline 1 & $-0,339$ & $-1,801$ & 0,084 \\
5 & $-0,022$ & $-0,111$ & 0,912 \\
2 & $-0,128$ & $-0,644$ & 0,525 \\
\hline
\end{tabular}

$\mathrm{R}$ - Coeficiente de correlação; to - $\mathrm{t}$ calculado; $\mathrm{p}$ - probabilidade (erro tipo I para a hipótese de nulidade)

Na tentativa de localizar a coerência ou incoerência entre os examinadores entre si, utilizou-se a estatística de teste de análise de componentes principais. O gráfico 5.1 demonstra claramente que os resultados dos examinadores 3 e 4 apresentam um certo grau de correlação com o resultado exato. Já os resultados dos examinadores 5,1 e 2 não se correlacionam com o controle. Esses resultados são confirmados quando se observa na tabela 5.4 que os valores positivos de coeficiente de correlação ( $R+)$ só são observados entre os examinadores 3 e 4 versus o resultado exato.

Em relação ao segundo questionamento, obteve-se $95,55 \%$ de respostas afirmativas pelos examinadores quanto o auxílio das telerradiografias em norma lateral e frontal no diagnóstico diferencial das calcificações quando observadas as imagens radiopacas nos locais sugestivos de calcificações em tecidos moles na radiografia panorâmica. 


\section{DISCUSSÃO}

A observação de imagens radiopacas adjacentes às regiões cervicais em radiografias panorâmicas teve considerável interesse nos últimos anos, principalmente em relação a presença de calcificações na região da artéria carótida. Segundo Carter (2000), o clínico deve distinguir ateromas calcificados de artéria carótida de radiopacidades anatômicas e patológicas que residem nestas proximidades. As radiopacidades anatômicas incluem o osso hióide, a epiglote, ligamentos estilo-hióideos e estilomandibulares mineralizados. As radiopacidades patológicas que podem apresentar-se na região da artéria carótida incluem cartilagem tireóidea calcificada, mais precisamente o corno superior, calcificação em glândula submandibular, flebólitos, gânglios linfáticos calcificados e tonsilolitos. Com base na localização e morfologia típica das entidades acima mencionadas, raramente há um problema em distingui-los a partir de ateromas calcificados. O propósito neste trabalho de pesquisa foi o de auxiliar na identificação dessas variabilidades e atentar para a existência dessas estruturas para reduzir assim a probabilidade de serem diagnosticados como ateromas calcificados de carótida. Para tanto, distribuímos referências radiopacas, inserindo-as nas estruturas em que acreditávamos estarem as maiores ocorrências de enganos e em seguida obtínhamos as radiografias panorâmicas, telerradiografias em norma lateral e frontal em cabeças de cadáveres. As referências radiopacas foram inseridas sobre as estruturas anatômicas propositadamente no mesmo nível da bifurcação da artéria carótida. De posse das imagens, submetemo-las a 05 radiologistas odontológicos, com 
experiência mínima de 5 anos, de forma que deveriam marcar, qual o local da calcificação ou da estrutura anatômica seria mais provável, das 81 radiografias entregues.

Segundo Carter (2000) muitos profissionais desconhecem que uma cartilagem tritícea calcificada, pode ser confundida com ateroma calcificado. Porém, os resultados do nosso estudo apontam que a referência radiopaca que estava localizada sobre a cartilagem tritícea obteve a maior percentagem de acerto (60\%) pelos examinadores na cabeça 01; $20 \%$ na cabeça 02 e $80 \%$ na cabeça 03. Desde Friedlander e Lande em 1981, em que determinaram a presença e a freqüência da ocorrência de placas ateroscleróticas nas radiografias panorâmicas, essas observações deram origem a um certo modismo entre os profissionais, de forma que toda e qualquer calcificação observada próxima a essa região, nas radiografias panorâmicas, fossem apontadas como ateromas de carótida (KAMIKAWA et al., 2006). Porém, nos últimos anos, os estudos realizados por autores como Ajmani (1990), Ajmani, Jain e Saxena (1980), Hately, Evison e Samuel (1965) e O'Bannon e Grunow (1954) têm sido utilizados como referências a respeito das calcificações da cartilagem tritícea e ainda os mais recentes tais como (AHMAD; MADDEN; PEREZ , 2005; AHMAD; MADDEN; EL-ASHIRY, 2002), enfatizando a importância desta estrutura anatômica quando no diagnóstico do local da radiopacidade.

Os resultados do nosso estudo apontam também acertos em relação à epiglote ( $40 \%$ nas cabeças $01 ; 02$ e 03 ) e da tonsila palatina (40 \% na cabeça $01 ; 60 \%$ na cabeça 02 e 80 \% na cabeça 03). A utilização das telerradiografias em norma frontal auxiliaram no diagnóstico, já que tais estruturas encontram-se localizadas mais centralmente ( Figura 4.5). 
Os resultados obtidos em nosso estudo corroboram com a observação de Carter (2000) de que as calcificações do corno superior da cartilagem tireóidea muitas das vezes são desconhecidas pelos cirurgiões-dentistas, pois em geral apenas a porção superior (2 a $3 \mathrm{~mm}$ ) dessa cartilagem calcificada é visível na borda inferior da radiografia panorâmica. Somente se o filme for posicionado além do limite inferior, será visualizado um comprimento maior dessa cartilagem. Em nossa pesquisa não houve acertos quando a referência radiopaca estava localizada sobre o corno superior da cartilagem tireóidea.

Até pouco tempo atrás apenas crianças e adolescentes eram submetidos a tratamentos ortodônticos utilizando radiografias cefalométricas. Há relatos de observação da imagem de cartilagem tireóide calcificada e ossificação da mesma por meio da radiografia cefalométrica (MUPPARAPU; VUPPALAPATI, 2002; SALMAN; KINNEY, 1990), mas a ossificação dessa cartilagem não ocorre antes da segunda década. Com a crescente procura de pacientes adultos na faixa etária de 20 a 60 anos de idade, para tratamentos ortodônticos acreditamos que a calcificação do corno superior da cartilagem tireóidea, quando ocorrer, poderá ser notada mais freqüentemente e facilmente pelos cirurgiões-dentistas.

No estudo realizado por Friedlander, Dounis e Gratt (1996) para determinar se as lesões calcificadas poderiam ser detectadas por meio de radiografias cefalométricas laterais convencionais, concluíram que tais radiografias poderiam demonstrar calcificações consistentes com aterosclerose de artéria carótida. O mesmo resultado não foi obtido em nosso estudo, já que a média de acertos pelos examinadores não foi constante em relação à referência radiopaca localizada na região da bifurcação da artéria carótida. Na cabeça 01 não houve acertos; na cabeça 02 o acerto foi de $60 \%$ e 
$20 \%$ para a cabeça 03 . Isto provavelmente ocorreu, pois é sabido que as calcificações em artéria carótida podem aparecer como uma massa radiopaca nodular, ou como duas linhas radiopacas verticais dentro das paredes da artéria, ao nível da margem inferior da terceira vértebra cervical (FRIEDLANDER; FRIEDLANDER, 1998) ou ainda, adjacentes, mas não contíguas, às terceira e quarta vértebras cervicais. Porém, na cabeça 01 a bifurcação encontrava-se à nível da segunda vértebra cervical (C2), o que é bastante raro. No estudo realizado por Klosek e Rungruang (2008) a maioria das bifurcações carotídeas foi encontrada em nível de C3, entre C3 e C4, e vértebra C4, bem como foi notado uma tendência para a posição mais inferior em homens. Neste estudo, a maior parte das bifurcações carotídeas encontrava-se no nível das vértebras C3 e C4, porém dois casos de alta bifurcação carotídea, à nível das vértebras C2 e C3 foram notadas unilateralmente, correspondendo a 2,7\% de todas as bifurcações carotídeas, o que pode ser explicado pela embriologia da artéria carótida interna à partir do segundo arco aórtico (SADLER, 1990). Segundo Gluncic et al. (2001) a incidência desta variação é rara, cerca de 1\%. Nos estudos de Anu et al. (2007) a bifurcação carotídea foi encontrada no nível de C2 em 10\% dos casos e apenas em 1\% estava no nível de C5.

Em relação ao segundo questionamento, mesmo a percentagem $95,55 \%$ de respostas afirmativas pelos examinadores quanto ao auxílio das telerradiografias em norma lateral e frontal no diagnóstico diferencial das calcificações, os acertos corresponderam aos coeficientes de correlação da intraclasse (ICC) inferiores à 0,40. 0 ICC pode ser classificado para nível de significado clínico como ruim $<0,40$, segundo Cicchetti e Sparrow (1981). 
Em estudo realizado anteriormente (KAMIKAWA et al., 2006), tivemos a dificuldade relacionada à qualidade da cabeça utilizada para a realização da pesquisa que nos foi gentilmente cedida pelo Departamento de Anatomia do ICB da USP, e essa era a única peça disponível e que possuía os requisitos necessários às nossas necessidades, mas a sua constituição física e/ou anatômica fugia à normalidade, pois possuía uma região cervical alongada no sentido crânio-caudal, dificultando inclusive até o próprio posicionamento no aparelho panorâmico. No presente estudo tivemos também dificuldade relacionada com a qualidade dos espécimes, os quais foram gentilmente cedidos pelo Departamento de Anatomia da Pontifica Universidade Católica do Paraná, já que estes ficam conservados em formol por longos anos, prejudicando a imagem radiográfica final. Os poucos acertos relacionados à cabeça 01 ocorreram devido a variação anatômica desse espécime, confirmando assim que em biótipos diferentes, existem dúvidas quanto a localização da calcificação. Pode-se justificar, ainda, a dificuldade dos acertos pela inserção das referências radiopacas, pois as mesmas foram posicionadas procurando sempre o mesmo nível da bifurcação da artéria carótida.

Neste estudo as referências radiopacas puderam ser inseridas na epiglote e na tonsila palatina o que não foram reproduzidas no trabalho anterior. Isso foi possível pela mudança da referência radiopaca, a qual tinha uma haste pontiaguda que serviu para fixação da mesma, já que o acesso até essas estruturas anatômicas eram difíceis e também pela colaboração técnica especializada para a realização da dissecação do espécime sem prejuízo de outras estruturas anatômicas. 


\section{CONCLUSÕES}

- As telerradiografias em norma lateral e frontal não contribuem eficazmente na identificação e localização de radiopacidades na região cervical;

- A conformação anatômica interfere na observação da presença de radiopacidade na região cervical. 


\section{REFERÊNCIAS ${ }^{1}$}

Affeld K, Goubergrits L, Fernandez-Britto J, Falcon L. Variability of the geometry of the human common carotid artery. A vessel cast study of 31 specimens. Pathol Res Pract 1998;194(9):597-602.

Ahmad M, Madden R, El-Ashiry K. Prevalence of carotid calcified atherosclerotic plaques on panoramic radiographs.J Dent Res 2002;82 Special Issue A:3990.

Ahmad M, Madden R, Perez L. Triticeous cartilage: prevalence on panoramic radiographs and diagnostic criteria. Oral Surg Oral Med Oral Pathol Oral Radiol Endod 2005;99(2):225-30.

Ajmani ML. A metrical study of the laryngeal skeleton in adult Nigerians. J Anat 1990;171:187-91.

Ajmani ML, Jain SP, Saxena SK. A metrical study of laryngeal cartilages and their ossification. Anat Anz 1980;148:42-8.

Almog DM, Illig KA, Carter LC, Friedlander AH, Brooks SL, Grimes RM. Diagnosis of non-dental conditions. Carotid artery calcifications on panoramic radiographs identify patients at risk for stroke. Y State Dent J 2004;70(8):20-5.

Alyas F, Lewis K, Williams M, Moody AB, Wong KT, Ahuja AT, Howlett DC. Diseases of the submandibular gland as demonstrated using high resolution ultrasound. $\mathrm{Br} \mathrm{J}$ Radiol 2005;78(928):362-9.

Amprino R, Bairati A. Studi sulle trasformazione delle cartilagini Del l'uomo nell'accrescimento e nella senescenza. Z Zellforsch Mikrosk Anat 1933;20:143-205.

\footnotetext{
${ }^{1}$ De acordo com Estilo Vancouver. Abreviatura de periódicos segundo base de dados MEDLINE
} 
Anu VR, Pai MM, Rajalakshmi R, Latha VP, Rajanigandha V, D'Costa S. Clinicallyrelevant variations of the carotid arterial system. Singapore Med J 2007;48(6):566-9.

Aspestrand F, Kolbenstvedt A. Calcifications of the palatine tonsillary region: CT demonstration. Radiology 1987;165:479.

Assadian A, Senekowitsch C, Pfaffelmeyer N, Assadian O, Ptakovsky H, Hagmüller GW. Incidence of cranial nerve injuries after carotid eversion endarterectomy with a transverse skin incision under regional anaesthesia. Eur J Vasc Endovasc Surg $2004 ; 28(4): 421-4$.

Bar T, Zagury A, London D, Shacham R, Nahlieli O. Calcifications simulating sialolithiasis of the major salivary glands. Dentomaxillofac Radiol 2007;36:59-62.

Bergman RA, Thompson SA, Afifi AK, Saadeh FA. Compendium of human anatomic variations. Baltimore:Urben and Schwarzenberg;1998.

Blair GS. Hydrostatic sialography: an analysis of a technique. Oral Surg Oral Med Oral Pathol 1973;36:116-30.

Bodner L. Salivary gland calculi. Diagnostic imaging and surgical management. Compend Contin Educ Dent 1993;14:572-84.

Carter LC. Discrimination between calcified triticeous cartilage and calcified carotid atheroma on panoramic radiography. Oral Surg Oral Med Oral Pathol Oral Radiol Endod 2000;90:108-10.

Cicchettl, DV, Sparrow, SS. Developing criteria for establishing interrater reliability of specific items: applications to assessment of adaptive behavior. Am J Ment Defic $1981 ; 86: 127-37$.

Cooper MM, Steinberg JJ, Lastra M, Antopol S. Tonsillar calculi.Report of a case and review of the literature. Oral Surg Oral Med Oral Pathol 1983;55(3):239-43.

Dedivitis RA, Abrahão M, Simões MJ, Mora AO, Cervantes O. Cricoarytenoid joint: histologic changes during aging. São Paulo Med J 2001;119:89-90. 
Drake RL, VogI W, Mitchell AWM. Gray's anatomy for Students. 1st ed. Edinburgh: Churchill Livingstone; 2005a.

Drake RL, VogI W, Mitchell AWM. Last's anatomy: regional and applied. 9th ed. London: Churchill Livingstone; 2005b.

European Carotid Surgery Trialists' Collaborative Group. Randomized trial of endarterectomy for recently symptomatic carotid stenosis: final results of MRC European Carotid Surgery Trial (ECST). Lancet 1998;351:1379-87.

Ferrario VF, Sigurta D, Daddona A, Dalloca L, Miani A, Tafuro F, Sforza C. Calcification of the stylohyoid ligament: Incidence and morphoquantitative evaluations. Oral Surg Oral Med Oral Pathol 1990;69(4):524-9.

Friedlander $\mathrm{AH}$. Identification of stroke-prone patients by panoramic and cervical spine radiography. Dentomaxillofac Radiol 1995;24(3):160-4.

Friedlander $\mathrm{AH}$, Altoman L. Carotid artery atheromas in postmenopausal women. JADA $2001 ; 132(8): 1130-6$.

Friedlander AH, Dounis G, Gratt BM. Lateral cephalometric radiographs: an aid in detecting patients at risk of stroke. J Am Dent Assoc 1996;127(12):1745-50.

Friedlander $\mathrm{AH}$, Friedlander IK. Identification of stroke prone patients by panoramic radiography. Aust Dent J 1998;43(1):51-4.

Friedlander AH, Gratt BM. Panoramic dental radiography as an aid in detecting patients at risk for stroke. J Oral Maxillofac Surg 1994;52(12):1257-62.

Friedlander $\mathrm{AH}$, Lande A. Panoramic radiographic identification of carotid arterial plaques. Oral Surg Oral Med Oral Pathol 1981;52(1):102-4.

Gelabert HA, Moore WS. Reducing the risk of stroke: identifying patients to refer for carotid endarterectomy. Geriatrics 1991;46(9):22-6.

Gerald M. Otolaryngology. Philadelphia: Harper\& Row; 1985. p.26-7. 
Giudice M, Cristofaro MG, Fava MG, Giudice A. An unusual tonsillolithiasis in a patient with chronic obstructive sialoadenitis. Dentomaxillofac Radiol 2005;34 (4):247-50.

Gluncic V, Petanjek Z, Marusic A, Gluncic I. High bifurcation of common carotid artery, anomalous origin of ascending pharyngeal artery and anomalous branching pattern of external carotid artery. Surg Radiol Anat 2001;23(2):123-5.

Gray H. Anatomy of the Human Body. Philadelphia: Lea \& Febiger; 1918. Disponível em: http://www.bartleby.com/107/236.html. Acesso em [2009 jun].

Graziani F, Vano M, Cei S, Tartaro GP, Mario G. Unusual asymptomatic giant sialolith of the submandibular gland: a clinical report. J Craniofac Surg 2006;17:549-52.

Grossman JW. The triticeous cartilages: a roentgen-anatomic study. Amer J Roentgenol 1945;53:166-70.

Grünebaum M, Ziv N, Mankuta DJ. Submaxillary sialadenitis with a calculus in infancy diagnosed by ultrasonography. Pediatr Radiol 1985;15(3):191-2.

Hately W, Evison G, Samuel E. The pattern of ossification in the laryngeal cartilages: a radiological study. Brit J Radiol 1965;38:585-91.

Hong Kong University. on-line statistical programs. Disponível em: URL: http://department.obg.cuhk.edu.hk/index.asp?scr=1024 [2009 maio 05].

Hori E, Hayashi N, Hamada H, Masuoka T, Kuwayama N, Hirashima Y, et al. A development of atheromatous plaque is restricted by characteristic arterial wall structure at the carotid bifurcation. Surg Neurol 2008;69(6):586-90.

Huang TC, Dalton JB, Monsour FN, Savage NW. Multiple, large sialoliths of the submandibular gland duct: a case report. Aust Dent J 2009;54(1):61-5.

Jurik AG. Ossification and calcification of the laryngeal skeleton. Acta Radiol Diagn 1984;25:17-22. 
Kamikawa RS, Pereira MF, Fernandes A, Meurer MI. Study of the localization of radiopacities similar to calcified carotid atheroma by means of panoramic radiography. Oral Surg Oral Med Oral Pathol Oral Radiol Endod 2006;101(3):374-8.

Kaneko K, Akita M, Murata E, Imai M, Sowa K. Unilateral anomalous left common carotid artery; a case report. Ann Anat 1996;178(5):477-80.

Kano M, Shimizu Y, Okayama K, Igari T, Kikuchi M. A morphometric study of agerelated changes in adult human epiglottis using quantitative digital analysis of cartilage calcification. Cells Tissues Organs 2005;180(2):126-37.

Klosek SK, Rungruang T. Topography of carotid bifurcation: considerations for neck examination. Surg Radiol Anat 2008;30(5):383-7.

Kornblut AD. Non-neoplastic diseases of the tonsils and adenoids. In: Paparella MM, Shumrick DA, Glucman JL, Meyerhoff WL. Otolaryngology. Philadelphia: WB Saunders;1991. p. 2141.

Langlais RP, Kasle MJ. Sialolithiasis: the radiolucent ones. Oral Surg Oral Med Oral Pathol 1975;40(5):686-90.

Langlais RP, Langland OE, Nortjé CJ. Diagnostic imaging of the jaws. Philadelphia: Williams \& Wilkins; 1995.

Langlais RP, Miles DA, Van Dis ML. Elongated and mineralized stylohyiod ligament complex: A proposed classification and report of a case of Eagle's syndrome. Oral Surg Oral Med Oral Pathol 1986;61(5):527-32.

Laufer A. The function of the epiglottis in speech. Lang Speech 1981;24:39-61.

Leung AKC, Choi MCK, Wagner GAL. Multiple sialoliths and a sialolith of unusual size in the submandibular duct. Oral Surg Oral Med Oral Pathol 1999;87(3):331-3.

Levy DM, Remine WH, Devine KD. Salivary gland calculi-pain, swelling associating with eating. J Am Med Assoc 1962;181:1115-9. 
Lewis DA, Brooks SL. Carotid artery calcification in a general population: a retrospective study of panoramic radiographs. Gen Dent 1999;47:98-103.

Lustmann J, Regev E, Melamed Y. Sialolithiasis. a survey on 245 patients and a review of the literature. J Oral Maxillofac Surg 1990;19:135-8.

Lustmann J, Shteyer A. Salivary calculi: ultrastructural morphology and bacterial etiology. J Dent Res 1981;60(8):1386-95.

Luyk NH, Doyle T, Ferguson MM. Recent trends in imaging the salivary glands. Dentomaxillofac Radiol 1991;20(1):3-10.

Mafee MF. CT of the normal larynx. Radiol Clin North Am 1984;22:251-64.

Mandel L. Multiple bilateral tonsilloliths: case report.Oral Maxillofac Surg 2008;66(1):148-50.

Mandel L. Tuberculous cervical node calcifications mimicking sialolithiasis: a case report. J Oral Maxillofac Surg 2006;64:1439-42.

Milroy CM. Ossification of the epiglottis. J Laryngol Otol 1992;106:180-2.

Mupparapu M, Vuppalapati A. Detection of an early ossification of thyroid cartilage in an adolescent on a lateral cephalometric radiograph. Angle Orthod 2002;72:576-8.

Mupparapu M, Vuppalapati A. Ossification of laryngeal cartilages on lateral cephalometric radiographs. Angle Orthod 2005;75(2):196-201.

Neshat K, Penna KJ, Shah D. Tonsillolith: a case report. J Oral Maxillofac Surg 2001;59:692-3.

Neville BW, Damm DD, Allen CM, Bouquot JE. Oral and Maxillofacial Pathology. $2^{\text {nd }}$ ed. Philadelphia: WB Saunders; 2002. 
New GB, Harper FR. Chronic inflamation of the salivary glands with or without calculi. Surg Gynecol Obstet 1931;53:456-60.

North American symptomatic carotid endarterectomy trial collaborators. Beneficial effect of carotid endarterectomy in symptomatic patients with high-grade carotid stenosis. $\mathrm{N}$ Engl J Med 1991;325:445-53.

O'Bannon RP, Grunow $\mathrm{OH}$. The larynx and pharynx radiologically considered. South Med J 1954;47:310-6.

Ohba T, Takata Y, Ansai T, Morimoto Y, Tanaka T, Kito S, et al. Evaluation of calcified carotid artery atheromas detected by panoramic radiograph among 80-year-olds. Oral Surg Oral Med Oral Pathol Oral Radiol Endod 2003;96(5):647-50.

Omnell KH, Gandhi C, Omnell ML. Ossification of the human styloid ligament. A longitudinal study. Oral Surg Oral Med Oral Pathol 1998;85(2):226-32.

Ord RA, Ward-Booth RP. Anomalies of the common carotid artery: a rare complication of radical neck dissection. Br J Oral Maxillofac Surg1986;24(6):405-9.

Özcan E, Ural A, Oktemer TK, Alpaslan G. Bilateral tonsillolithiasis: a case report.Oral Surg Oral Med Oral Pathol Oral Radiol Endod 2006;102(3):e17-e8.

Ozgur Z, Govsa F, Ozgur T. Anatomic evaluation of the carotid artery bifurcation in cadavers: implications for open and endovascular therapy. Surg Radiol Anat 2008;30(6):475-80.

Pornprasertsuk-Damrongsri S, Thanakun S. Carotid artery calcification detected on panoramic radiographs in a group of Thai population. Oral Surg Oral Med Oral Pathol Oral Radiol Endod 2006;101:110-5.

Pruet CW, Duplan DA. Tonsil concretions and tonsilloliths. Otolarygol Clin North Am 1987;20:305-9.

Ram S, Siar CH, Ismail SM, Prepageran N. Pseudo bilateral tonsilloliths: a case report and review of the literature. Oral Surg Oral Med Oral Pathol Oral Radiol Endod 2004;98(1):110-4. 
Rauch S, Gorlin RJ. Diseases of the salivary glands. In: Gorlin RJ, Goldman HM. Thoma's oral pathology. $6^{\text {th }}$ ed. St. Louis: CV Mosby; 1970.

Revel MP, Bely N, Laccourreye O, Naudo P, Hartl D, Brasnu D. Giant tonsillolith. Ann Otol Rhinol Laryngol 1998;107(3):262-3.

Roberts LK, Gerald B. Absence of both common carotid arteries. AJR Am J Roentgenol 1978;130(5):981-2.

Romano-Sousa CM, Krejci L, Medeiros FM, Graciosa-Filho RG, Martins MF, Guedes $\mathrm{VN}$,et al. Diagnostic agreement between panoramic radiographs and color Doppler images of carotid atheroma. J Appl Oral Sci 2009;17(1):45-8.

Sadler TW. Langman's medical embryology. $6^{\text {th }}$ ed. Baltimore: Williams and Wilkins; 1990.

Salman RA, Kinney LA. Calcified thyroid cartilage. Oral Surg Oral Med Oral Pathol 1990;70(6):806-7.

Scaf G, Freitas DQ, Loffredo LCM. Diagnostic reproducibility of the elongated styloid process. J Appl Oral Sci 2003;11(2):120-4.

Schulz UG, Rothwell PM. Major variation in carotid bifurcation anatomy: a possible risk factor for plaque development? Stroke 2001;32(11):2522-9.

Seward GR. Anatomic surgery for salivary calculi. Oral Surg Oral Med Oral Pathol 1968;26:137-44.

Shetty D, Lakhkar B, Shetty CM. Images: Tonsillolith. Ind J Radiol Imag 2001;11:31-2.

Silvestre-Donat FJ, Pla-Mocholi A, Estelles-Ferriol E, Martinez-Mihi V. Giant tonsillolith: Report of a case. Med Oral Patol Oral Cir Bucal 2005;10(3):239.

Smith D, Larsen JL. On the symmetry and asymmetry of the bifurcation of the common carotid artery: a study of bilateral carotid angiograms in 100 adults. Neuroradiology 1979;17(5):245-7. 
Stafne EC, Gibilisco JA. Diagnóstico radiográfico bucal de Stane. $5^{\mathrm{a}}$ ed. Rio de Janeiro: Interamerica; 1986:137-9

Suarez-Cunqueiro MM, Duker J, Liebehenschel N, Schön R, Schmelzeisen R. Calcification of the branches of the external carotid artery detected by panoramic radiography: A case report. Oral Surg Oral Med Oral Pathol Oral Radiol Endod 2002;94 (5):636-40.

Suarez-Cunqueiro MM, Dueker J, Seoane-Leston J, Schmelzeisen R. Tonsilloliths associated with sialolithiasis in the submandibular gland. Oral Maxillofac Surg 2008;66(2):370-3.

Tamura T, Inui M, Nakase M, Nakamura S, Okumura K, Tagawa T. Clinicostatistical study of carotid calcification on panoramic radiographs. Oral Dis 2005;11(5):314-7.

Taylor E. Dorland's Illustrated medical dictionary. $27^{\text {th }}$ ed. Philadelphia: W.B. Saunders; 1988.

Trigaux JP, Delchambre F, Van Beers B. Anatomical variations of the carotid bifurcation: implications for digital subtraction angiography and ultrasonography. Br J Radiol 1990;63(747):181-5.

Vitek JJ, Reaves P. Thoracic bifurcation of the common carotid artery. Neuroradiology 1973;5(3):133-9.

Waite DE. Secretory sialography of the salivary glands. Oral Surg Oral Med Oral Pathol 1969;27:635-41.

Weller CV. The incidence and pathogenesis of tonsillar concretions. Ann Otol Rhinol Laryngol 1924;33:79.

Westmore B, Hupp J. Tonsillolith. Oral Surg Oral Med Oral Pathol 1988;65(6):783.

Williams MF. Sialolithiasis. Otolaryngol Clin North Amer 1999;32(5):819-34. 
Wittich GR, Scheible WF, Hajek PC. Ultrasonography of the salivary glands. Radiol Clin North Am 1985;23(1):29-37.

Yadav JS, Wholey MH, Kuntz RE, Fayad P, Katzen BT, Mishkel GJ, et al. Stenting and Angioplasty with Protection in Patients at High Risk for Endarterectomy Investigators. Protected carotid-artery stenting versus endarterectomy in high-risk patients. N Engl J Med 2004;351(15):1493-501.

Yerman HM, Werkhaven J, Schild JA. Evaluation of laryngeal calcium deposition: a new methodology. Ann Otol Rhinol Laryngol 1988;97:516-20.

Yune HY, Klatte EC. Current status of sialography. Am J Roentgenol Radium Ther Nucl Med 1972;115(2):420-8.

Zarins CK, Giddens DP, Bharadvaj BK, Sottiurai VS, Mabon RF, Glagov S. Carotid bifurcation atherosclerosis. Quantitative correlation of plaque localization with flow velocity profiles and wall shear stress. Circ Res 1983;53(4):502-14. 
ANEXO A - Parecer do Comitê de Ética em Pesquisa

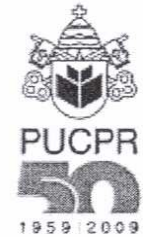

\author{
PONTIFÍCIA UNIVERSIDADE CATÓLICA DO PARANÁ \\ Núcleo de Bioética \\ Comitê de Ética em Pesquisa
}

PARECER CONSUBSTANCIADO DE PROTOCOLO DE PESQUISA

Parecer No 0001920/08

Protocolo CEP No 2477

Titulo do projeto Avaliação radiográfica da região cervical na pesquisa da calcificações em tecidos por meio de diferentes técnicas radiográficas

Grupo III

Protocolo CONEP 0267.0.084.084-08

Pesquisador responsável Rosangela Sayuri Saga Kamikawa Instituição

Objetivos

Determinar se a utilização de telerradiografias laterais e frontais oferece resultados conclusivos da existência ou não do ateroma, quando este já tiver sido observado nas radiografias panorâmicas.

\title{
Comentátios
}

O projeto visa, através da análise de radiografias, de arquivo e de material cadavérico, levantar a possibilidade de constataçãode placas de ateromas e outras complicações vasculares.

\section{Considerações}

O projeto está bem delineado e com metodologia adequada. Fará uso de radiografias e de cadáveres.

Termo de consentimento livre e esclarecido

Não é necessário, visto a natureza do estudo.

\section{Conclusões}

O projeto atende a RES. 196/96 do CNS.

Devido ao exposto, o Comitê de Ética em Pesquisa da PUCPR, de acordo com as exigências das Resoluções Nacionais 196/96 e demais relacionadas a pesquisas envolvendo seres humanos, em reunião realizada no dia: 20/08/2008, manifesta-se por considerar o projeto Aprovado.

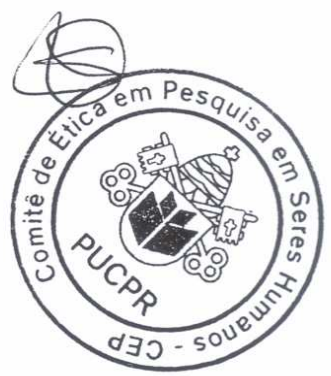


Parecer No 0001920/08

Protocolo CEP NO 2477

Titulo do projeto Avaliação radiográfica da região cervical na pesquisa da calcificações

em tecidos por meio de diferentes técnicas radiográficas

Grupo III

Protocolo CONEP 0267.0.084.084-08

Pesquisador responsável Rosangela Sayuri Saga Kamikawa

Instituição

Situação Aprovado

Lembramos aos senhores pesquisadores que, no cumprimento da Resolução 196/96, o Comitê de Ética em Pesquisa (CEP) deverá receber relatórios anuais sobre o andamento do estudo, bem como a qualquer tempo e a critério do pesquisador nos casos de relevância, além do envio dos relatos de eventos adversos, para conhecimento deste Comitê. Salientamos ainda, a necessidade de relatório completo ao final do estudo.

Eventuais modificações ou emendas ao protocolo devem ser apresentadas ao CEP-PUCPR de forma clara e sucinta, identificando a parte do protocolo a ser modificado e as suas justificativas.

Se a pesquisa, ou parte dela for realizada em outras instituições, cabe ao pesquisador não iniciá-la antes de receber a autorização formal para a sua realização. 0 documento que autoriza o início da pesquisa deve ser carimbado e assinado pelo responsável da instituição e deve ser mantido em poder do pesquisador responsável, podendo ser requerido por este CEP em qualquer tempo.

Curitiba, 20 de Agosto de 2008.

Prof. Dr. Sergio Surugi de Siqueira

Coordenador do Comitê de Ética em Pesquisa PUCPR

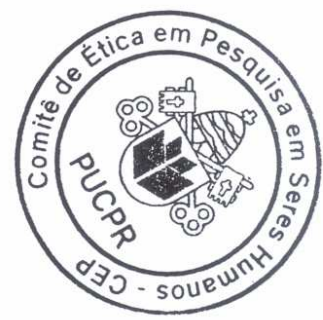


ANEXO B - Parecer do Comitê de Ética em Pesquisa

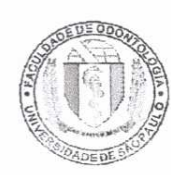

Universidade de São Paulo

Fraculdade de Odontologia

Comitê de Ética em Pesquisa

\section{DE CLARAÇ Ã O \\ PROTOCOLO CEP NO. 2477 \\ PARECER NO. 0001920/08 \\ Protocolo CONEP 0267.0.084.084-08 \\ Aprovado em 20/08/2008}

Informamos a Vossa Senhoria, que diante de

Parecer do Comitê de Ética em Pesquisa do Núcleo de Bioética da Pontifícia Universidade Católica do Paraná, estamos cientes da aprovação do projeto de pesquisa intitulado "Avaliação radiográfica da região cervical na pesquisa da calcificações em tecidos por meio de diferentes técnicas radiográficas" de responsabilidade do(a) Pesquisador(a) Rosangela Sayuri Saga Kamikawa, sob orientação do(a) Professor(a) Doutor(a) Marlene Fenyo Soeiro de Matos Pereira.

Sendo o que se nos apresentava, valemo-nos da oportunidade para reiterar-Ihe os nossos protestos de elevada estima e distinta consideração.

São Paulo, 04 de dezembro de 2008.

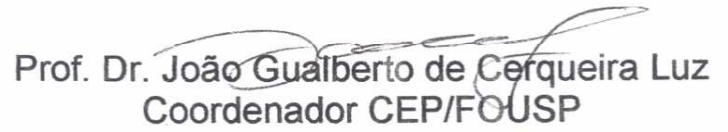


APÊNDICE A - Questionário 01 entregue aos radiologistas

01-Utilizando as telerradiografias em norma lateral e frontal e as radiografias panorâmicas, assinale qual a localização mais provável da referência radiopaca. Identifique com as letras do alfabeto utilizando o quadro ao lado.

\begin{tabular}{|c|c|c|}
\hline cabeça & Radiog & Examinador \\
\hline 1 & 1 & \\
\hline 1 & 2 & \\
\hline 1 & 3 & \\
\hline 1 & 4 & \\
\hline 1 & 5 & \\
\hline 1 & 6 & \\
\hline 1 & 7 & \\
\hline 1 & 8 & \\
\hline 1 & 9 & \\
\hline 2 & 1 & \\
\hline 2 & 2 & \\
\hline 2 & 3 & \\
\hline 2 & 4 & \\
\hline 2 & 5 & \\
\hline 2 & 6 & \\
\hline 2 & 7 & \\
\hline 2 & 8 & \\
\hline 2 & 9 & \\
\hline 3 & 1 & \\
\hline 3 & 2 & \\
\hline 3 & 3 & \\
\hline 3 & 4 & \\
\hline 3 & 5 & \\
\hline 3 & 6 & \\
\hline 3 & 7 & \\
\hline 3 & 8 & \\
\hline 3 & 9 & \\
\hline
\end{tabular}


APÊNDICE B - Questionário 02 entregue aos radiologistas

02- Em sua opinião, nos casos apresentados, ao observar as imagens radiopacas nos locais sugestivos de calcificações em tecidos moles na radiografia panorâmica, as telerradiografias em norma lateral e frontal, auxiliaram no diagnóstico diferencial destas calcificações? Responda S (sim) ou N (não).

\begin{tabular}{|c|c|c|}
\hline cabeça & Radiog & Examinador \\
\hline 1 & 1 & \\
\hline 1 & 2 & \\
\hline 1 & 3 & \\
\hline 1 & 4 & \\
\hline 1 & 5 & \\
\hline 1 & 6 & \\
\hline 1 & 7 & \\
\hline 1 & 8 & \\
\hline 1 & 9 & \\
\hline 2 & 1 & \\
\hline 2 & 2 & \\
\hline 2 & 3 & \\
\hline 2 & 4 & \\
\hline 2 & 5 & \\
\hline 2 & 6 & \\
\hline 2 & 7 & \\
\hline 2 & 8 & \\
\hline 2 & 9 & \\
\hline 3 & 1 & \\
\hline 3 & 2 & \\
\hline 3 & 3 & \\
\hline 3 & 4 & \\
\hline 3 & 5 & \\
\hline 3 & 6 & \\
\hline 3 & 7 & \\
\hline 3 & 8 & \\
\hline 3 & 9 & \\
\hline
\end{tabular}

